\title{
IN VITRO IN VIVO STUDIES ON FLOATING MICROSPHERES FOR GASTRORETENTIVE DRUG DELIVERY SYSTEM: A REVIEW
}

\author{
KRISHNA $^{1}$, ABHISHEK KUMAR ${ }^{1 *}$, RAJAT SRIVASTAVA ${ }^{2}$ \\ ${ }^{1}$ Department of Pharmacy, Ashoka Institute of Technology and Management, Varanasi, Uttar Pradesh, India. ${ }^{2}$ Department of Pharmacy, \\ ARK College of Pharmacy, Kaushambi, Uttar Pradesh, India. Email: abhishekaitm641@gmail.com
}

Received: 22 July 2020, Revised and Accepted: 19 November 2020

\section{ABSTRACT}

The purpose of writing this review on gastroretentive drug delivery systems (GRDDS) was to compile the recent literature with a special focus on various gastroretentive approaches that have recently become leading methodologies in the field of site-specific orally administered controlled release drug delivery. One of the complex processes in the human body is gastric emptying, as it is highly variable, which makes the in vivo performance of the drug delivery systems uncertain. GRDDS has gained immense popularity in the field of oral drug delivery recently. It is a widely employed approach to retain the dosage form in the stomach for an extended period of time and release the drug slowly that can address many challenges associated with the conventional oral delivery system. Conventional drug delivery systems may not overcome the issues imposed by the gastrointestinal tract (GIT) such as incomplete release of drugs, decrease in dose effectiveness, and frequent dose requirement. To overcome this variability, a controlled drug delivery system with a prolonged gastric residence time of $>12 \mathrm{~h}$ in the stomach can be of great practical importance for drugs with an absorption window in the upper small intestine. GRDFs enable prolonged and continuous release of the drug to the upper part of the GIT and thus significantly extend the duration of drug release and improve the bioavailability of drugs that have a narrow therapeutic window; by this way, they prolong dosing interval and increase compliance.

Keywords: Gastroretentive, Floating microsphere, Gastric residence time, Therapeutic window.

(C) 2021 The Authors. Published by Innovare Academic Sciences Pvt Ltd. This is an open access article under the CC BY license (http://creativecommons.org/ licenses/by/4.0/) DOI: http://dx.doi.org/10.22159/ajpcr.2021v14i1.39183. Journal homepage: https://innovareacademics.in/journals/index.php/ajpcr

\section{INTRODUCTION}

\section{Gastroretentive drug delivery system (GRRDS)}

Oral controlled-release (CR) dosage forms (DFs) were developed over the past three decades due to their therapeutic benefits, for example, ease of administration, patient compliance, and malleability to the formulation.

However, this is due to several physiological difficulties such as the inability to bring under control and detect controlled drug delivery systems within the preferred region of the gastrointestinal tract (GIT) due to variable gastric emptying and motility Fig. 1.

Besides, relatively brief gastric emptying time (GET) in humans that typically averages $2-3 \mathrm{~h}$ through the main absorption zone, that is, the stomach and the upper part of the intestine, in releasing incomplete medication from the drug delivery system can release efficacy of the administered dose [1].

For more than half a century, pharmaceutical scientists have focused on the development of ideas to increase the gastric residence time of DFs [2]. The prolonged residence of DFs in the stomach, known as gastric retention, has various therapeutic and biopharmaceutical properties. Improvement of local activity in the stomach, increased concentrations in the stomach, increased patient compliance due to dose reduction or improved bioavailability of some drugs with windows in the upper GIT [3].

The DFs that can be maintained in the stomach are called gastrointestinal drug delivery systems (GRDDS). Controlled delivery of drugs can improve the absorption window as shown in Fig. 2. Prolonged gastric retention improves bioavailability, reduces residual waste, and increases the solubility of drugs soluble in the high $\mathrm{pH}$ environment of the GIT. This includes applications for local delivery of the stomach and small intestine [4].

\section{ANATOMY OF THE GIT}

The GIT can be divided into three main areas:

1. Stomach

2. Small intestine - duodenum, jejunum, and ileum

3. Large intestine.

The GIT is a continuous muscular tube, which extends from the mouth to the anus, which serves to take nutrients and eliminate waste by such physiological processes as secretion, motility, digestion, absorption, and excretion. The stomach is a J-shaped enlargement of the gut GIT that can be divided into four anatomic regions: The cardia, fundus, body, and antrum. The main function of the stomach is to store and mix food with gastric secretions before emptying its load (chime) through the pyloric sphincter and into the small intestine at a controlled rate suitable for digestion and absorption. When empty, the stomach has a volume of about $50 \mathrm{ml}$, [5] it can grow up to $1 \mathrm{~L}$ when full. The walls of the GIT, from the stomach to large intestine, have the same basic arrangement of tissues, different layers, from outside to inside, including the serosa, longitudinal muscle, endocrine planetary, circular muscle, submucosa, muscular mucosa, lamina propria, and contains epithelium [6].

In addition to longitudinal and circular muscle, the stomach has a third muscle layer known as the "oblique muscle layer," which is located in the proximal stomach, branching above the fundus and upper regions of the gastric body. The different smooth muscle layers are responsible for performing the cruise functions of the gastric emptying and intestinal transit, that is, GIT.

\section{MUCUS: STRUCTURE, FUNCTION, AND COMPOSITION}

Mucus is a complex viscous adjacent secretion synthesized by specialized goblet cells. These goblet cells are glandular columnar epithelium cells and line all organs, exposure to the external environment [7]. Mucus is a complex viscous adjacent secretion synthesized by specialized goblet cells. These goblet cells are glandular columnar epithelium cells and line 


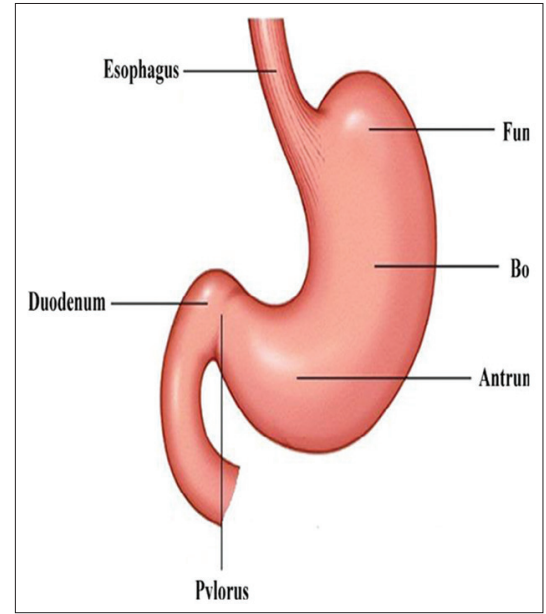

Fig. 1: Diagram of the human stomach

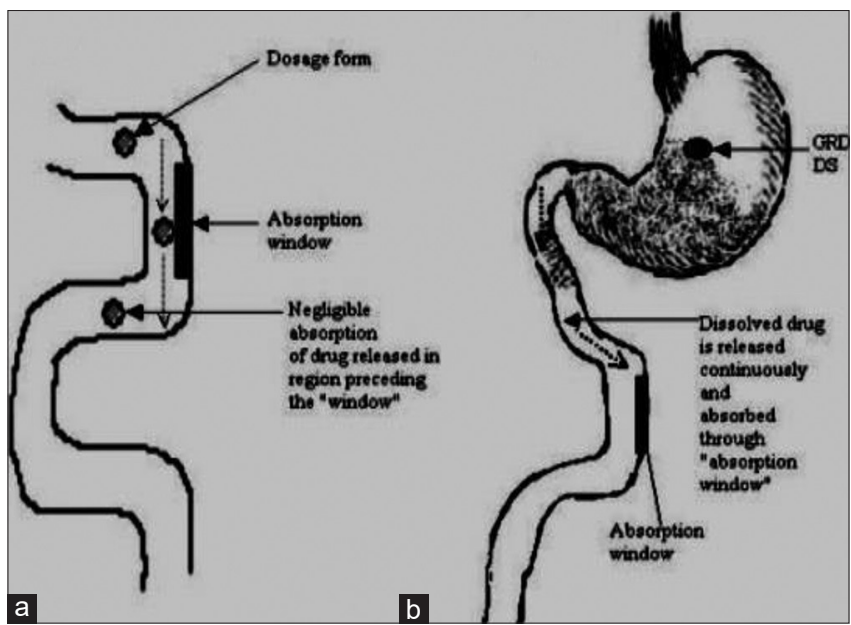

Fig. 2: Drug absorption from (a) conventional dosage forms and (b) gastroretentive drug delivery system [12]

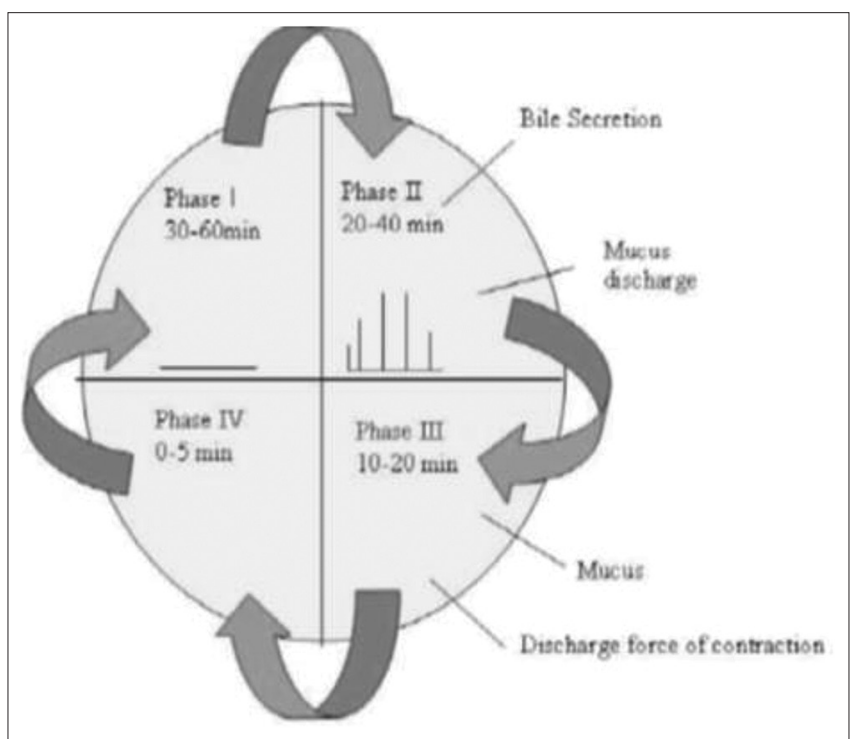

Fig. 3: Motility patterns of the gastrointestinal tract in the fasted state

all organs, exposure to the external environment. Mucus is found to carry out many functions within these locations, for instance, lubrication for the passage of objects, maintenance of a hydrated epithelium layer, a barrier function concerning pathogens and toxins, and as a gel layer allowing for the exchange of gases and nutrients from the underlying epithelium [8].

Mucus is composed mainly of water (>95\%) and mucin, which is composed of an exceptionally high molecular weight $(2-14 \times 106 \mathrm{~g} /$ mol) of glycoprotein. Also found within this "viscoelastic soup" are proteins, lipids, and mucopolysaccharides, which are found in smaller proportions $(<1 \%)$. Mucin glycoproteins form a highly entangled network of macromolecules that bind to each other via non-covalent bonds. Such a molecular association is central to the structure of mucus and is responsible for its rheological properties. Besides, the mucosa is treated as ionic polyelectrolyte in the reduction of pendant sialic acid $(\mathrm{pKa}=2.6)$ and sulfate groups located on glycoprotein molecules [9]

Other non-mucin components of mucus include secretory IgA, lysozyme, lactoferrin, lipids, polysaccharides, and various other ionic species. Some of these non-mucin components are believed to be responsible for the bacteriostatic mucus [10]

\section{POTENTIAL DRUG CANDIDATES FOR GRDDS}

- A small window in the GI tract, for example, riboflavin and levodopa

- It is primarily absorbed from the stomach and upper part of GIT, for example, calcium supplements, chlordiazepoxide, and cinnarizine

- Drugs that act locally in the stomach, such as antacids and misoprostol

- Drugs that degrade in the colon, such as ranitidine $\mathrm{HCl}$ and metronidazole

- Drugs that disturb common colonic bacteria, for example, amoxicillin trihydrate

- Low-density form of the DF that causes buoyancy in gastric fluid

- High-density DF that remains intact in the bottom of the stomach

- Bioadhesion to abdominal mucosa

- Slow motility of the GIT by concomitant administration of drugs or excipients

- Inflammation or spread of a larger size that limits DF emptying through the pyloric sphincter [11].

\section{BASIC GIT PHYSIOLOGY}

Anatomically, the stomach is divided into three areas: fundus, body, and antrum (pylorus). The fundus and the proximal part of the body act as a reservoir of non-digestible substances, while the antrum is the main site for a combination of movements and acts as a pump for gastric emptying through the moving process. Gastric emptying occurs in fasting and feeding states. However, the dynamics of the two states are different. During a state of fasting, cycling through the stomach and intestines, a series of electrical events occur every 2-3 h. This is called the Inter-Digestive Milo Electric Cycle or Migrating Milo Electric Cycle (MMC), which is divided into the following four steps described by Wilson and Washington (1989).

1. Phase I (basal stage) lasts 40-60 min with rare contractions

2. Phase II (pre-burst phase) often lasts 40-60 min with action potentials and contractions. As the phase increases, the intensity and frequency and frequency gradually increase

3. Phase III (burst phase) lasts 4-6 min. It involves short-term severe and frequent contractions. This wave touches everything from the stomach to the small intestine. This is also known as the housekeeper wave

4. Phase IV lasts from zero to five minutes and takes place between two cycles of Phase III and I, respectively Fig. 3 [13].

After a mixed meal, the method of contractions varies from fasting to feeding. This is also known as the digestive movement pattern and has frequent contractions such as the second stage of the fasting phase. As a result of these contractions, the size of the food particle is reduced $(<1 \mathrm{~mm})$, leading to pylorus in suspension form. In a fed state, MMC initiation is delayed, which reduces the gastric emptying rate. Scientific studies determining gastric emptying rates have shown that orallyCR DFs are two problems, namely low GET and unexpected gastric emptying rate $[14,15]$. 


\section{APPROACHES TO GASTRIC RETENTION}

Many methods have been used to increase the gastric retention time (GRT) of the DF in the stomach by applying a variety of concepts. These include in Fig. 4.

\section{FLOATING SYSTEMS}

Floating systems are low-concentration systems that are buoyant enough for the stomach to flow above the gastric contents. When the system flows above the gastric contents, the rate is slowly released at the desired rate, thereby increasing gastroretention time and reducing fluctuations in plasma drug concentrations [16,17].

\section{BIO/MUCOADHESIVE SYSTEMS}

The bio/mucoadhesive system (Fig. 5) works as a means of increasing the gastric residence time of the drug delivery system in the stomach by binding to the gastric epithelial cell surface or with mucins. The binding of polymers to the mucous/epithelial surface can be classified into three broad categories:

- Hydration-mediated compliance

- Bond-mediated compilation

- Receptor-mediated synthesis [16].

\section{SWELLING AND EXPANDING SYSTEMS}

These are DFs that prevent the outflow of pylorus after swallowing. As a result, the DF lasts longer in the stomach. These systems can be named "plug type systems" because they show a tendency to penetrate the pyloric sphincter Fig. 6 [18].

\section{HIGH-DENSITY SYSTEMS}

These systems Fig. 7, with a density of about $3 \mathrm{~g} / \mathrm{cm}^{3}$, persist in the abdominal cavities and can prevent its gradual contraction. A density of $2.6-2.8 \mathrm{~g} / \mathrm{cm}^{3}$ serves as a threshold value after which such systems can be maintained in the lower abdomen. High-density aggregates include coated pellets. The coating is made of heavy inert substances such as barium sulfate, zinc oxide, titanium dioxide, and iron powder [19].

\section{INCORPORATION OF PASSAGE DELAYING FOOD AGENTS}

Edible excipients such as fatty acids, for example, the salts of myristic acid, alter and modify the outline of the stomach in a tight state, thus reducing the rate of gastric emptying and prolonging the release. The delay in gastric emptying after the fatty diet is primarily a chain length of saturated fatty acids of C10-C14.

\section{ION EXCHANGE RESINS}

Ion exchange resins are loaded with bicarbonate and bind to a negatively charged drug residue. The resulting beads are then encapsulated into a semi-permeable membrane to overcome the rapid loss of carbon dioxide. When it reaches the acidic environment of the stomach, there are ions exchange of chlorides and bicarbonates occour. As a result of this reaction, carbon dioxide is released into the membrane, producing a temporary layer of resin beads, which, unlike the unbleached beads, causes the beads to rise above the gastric contents.

\section{OSMOTIC REGULATED SYSTEMS}

It is equipped with an osmotic pressure controlled drug delivery device inflatable floating support in a biodegradable capsule. The capsule in the stomach quickly disintegrates, leaving the intragastric osmotically controlled drug delivery device. The inflatable support inside forms a malfunctioning hollow polymer bag containing a liquid that gasifies to inflame the bag at body temperature. The osmotic controlled drug delivery device has two components - the drug store and the osmotically active compartment [16].

\section{FLOATING DRUG DELIVERY SYSTEMS}

Floating drug delivery systems or hydrodynamic balance systems have a lower density than abdominal fluid and stay in the stomach for longer without affecting the rate of miscarriage Fig. 4. The drug is slowly released from the system at the desired rate and the other drug is released into the stomach. This results in better control of the duration of stay in the stomach and the suitability of plasma drug concentrations [20].

Floating systems are low-level systems that have enough courage to float beyond the stomach contents and remain in the stomach for longer. When the system floats above the contents of the stomach, the drug is released slowly at the desired rate, leading to an increase in intestinal storage time and a decrease in changes in plasma drug concentrations [21]

\section{MAGNETIC SYSTEM [16,22]}

DFs contain a small internal magnet and a magnet is placed in the abdomen over the position of the stomach that retains DF in the gastric region.

\section{Disadvantage}

- The external magnet needs to be positioned with a degree of precision

- Patient non-compliance

- Not widely used.

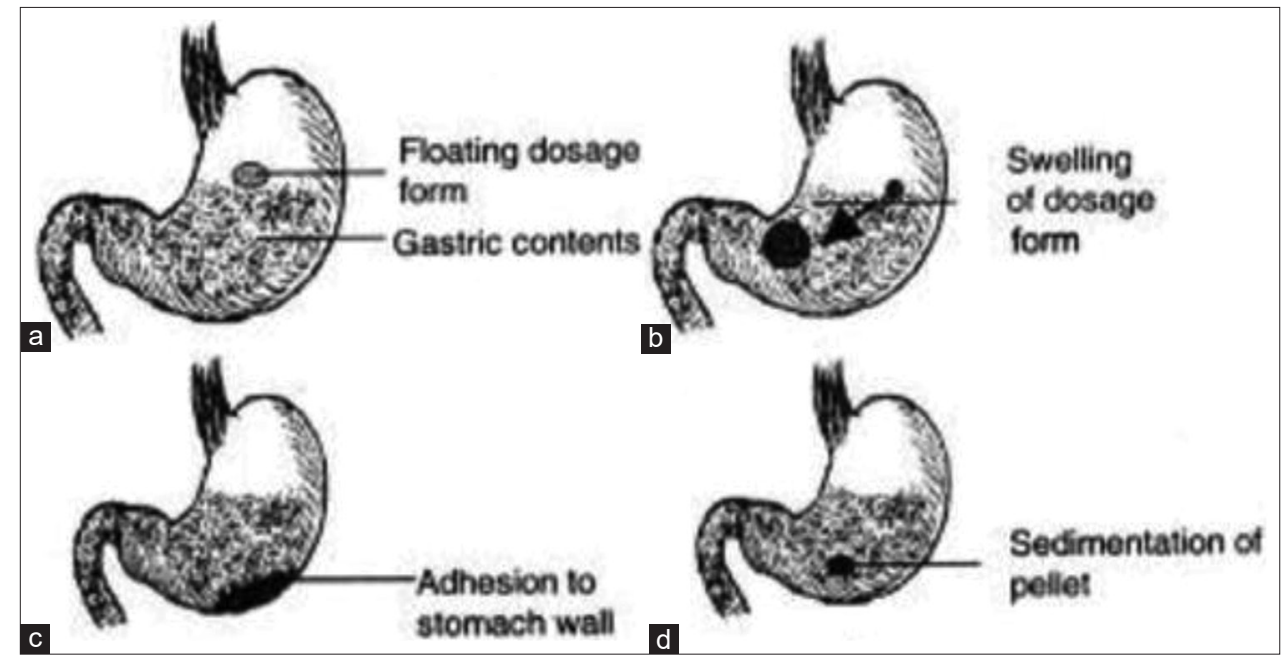

Fig. 4: (a-d) Illustration of types of gastroretentive drug delivery systems 


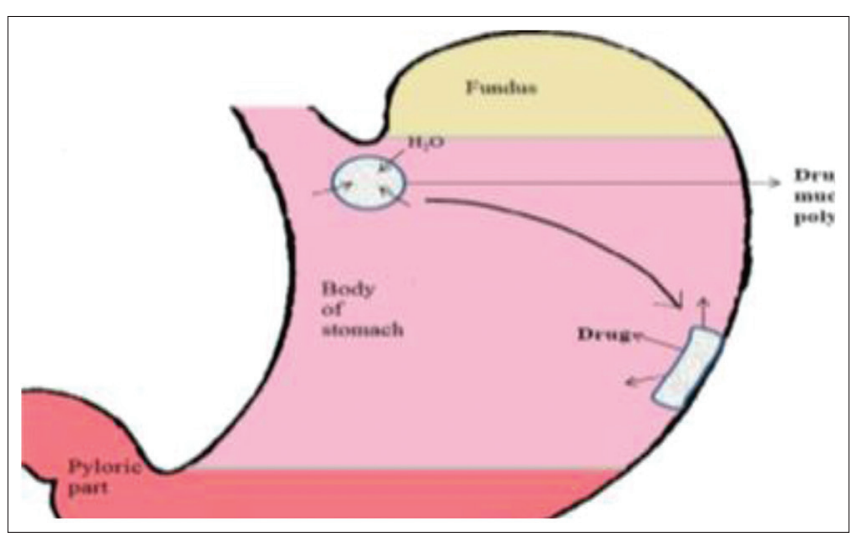

Fig. 5: Gastroretentive drug delivery system based on mucoadhesion

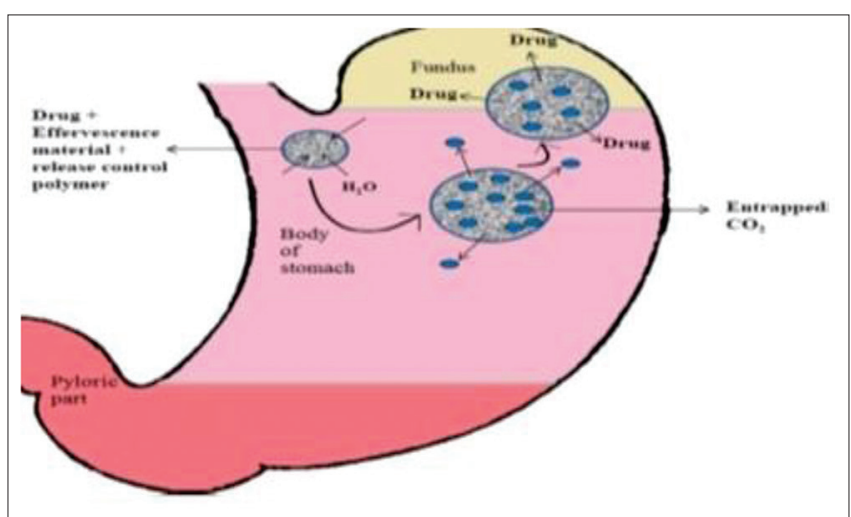

Fig. 6: Gastroretentive drug delivery system based on the combination of polymer swelling and effervescence

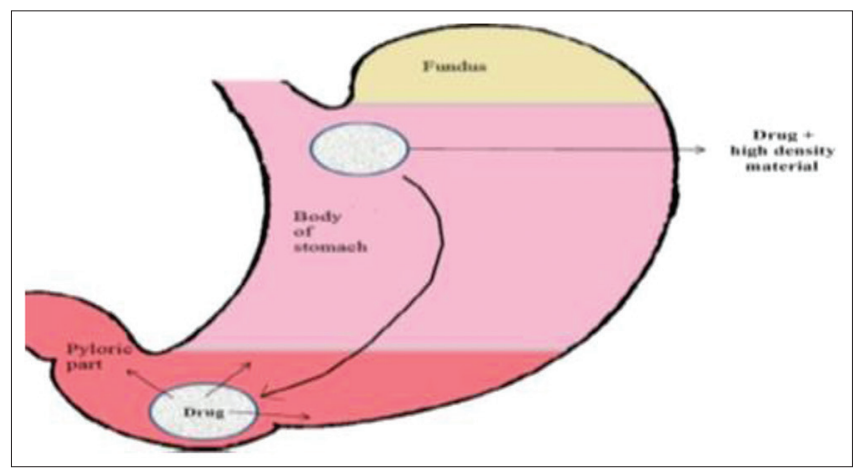

Fig. 7: Gastroretentive drug delivery system based on high density

Types of floating drug delivery system: FDDS can be divided into two systems:

1. Effervescent systems

2. Non-effervescent systems.

\section{Effervescent systems}

Volatile liquid containing systems

The GRT of the drug delivery system can be maintained by incorporating a fluidized inflatable chamber, namely, ether and cyclopentane, which is gasified at body temperature for infection in the abdominal chamber. The device may also contain biodegradable plugs made of poly (vinyl) alcohol, polyethylene, etc., causing the inflatable chamber to slowly melt and fall with gas and collapse after a predetermined time to allow spontaneous rejection of the inflatable system from the stomach [22].
Gas-generating systems

These buoyant delivery systems use reactions expressed between carbonate/bicarbonate salts and citric/tartaric acid to release $\mathrm{CO}_{2}$, which is trapped in the gelified hydrochloride layer of the system, thus reducing its specific gravity and it floats on the chime [23,24]. These incandescent systems contain soluble polymers such as methocel and polysaccharides such as chitosan, sodium bicarbonate, citric acid, and waste components such as tartaric acid or a liquid-containing chamber that is gasified at body temperature. The optimum stoichiometric ratio of citric acid and sodium bicarbonate for gas production is reported to be $0.76: 1$. Common approaches to formulate these systems include bicarbonate-filled resin structures and coated with ethyl cellulose. The coating, which is insoluble but permeable, allows water to penetrate. Thus, carbon dioxide is released, allowing the beads to float in the stomach. Other approaches and reported materials are a mixture of highly soluble hydrocarbons and light mineral oils, a mixture of sodium alginate and sodium bicarbonate, multiple-unit floating tablets that produce carbon dioxide when sodium bicarbonate, mini capsules floating with a core of lactose and polyvinyl pyrrolidone coated with hydroxypropyl methylcellulose (HPMC), and floating systems based on ion exchange resin technology, etc.

\section{Non-effervescent systems}

This mechanism, after swallowing, causes irregular inflammation by absorbing gastric fluid, preventing it from exiting the stomach. These systems can be referred to as plug type systems because they tend to stay close to the pyloric sphincter. One method of manufacturing such DFs involves mixing the drug with gel, exposed to gastric fluid after oral administration, and maintaining relative integrity of size and less than a bulk density in the external gelatinous barrier. The air trapped by the inflamed polymer delights these DFs.

\section{Colloidal gel barrier systems}

Hydrodynamically balanced system was the first design by Sheth and Tossounian in 1975. Such systems consist of hydrochlorides with drug-containing gel compositions, which mean that the contents of the stomach remain sharp. This system contains high levels of one or more gels that form highly soluble cellulose type hydrocarbons, namely, HECs, HPMCs, NACMCs, polysaccharides, and polymers form matrices such as polycarbophil, polyacrylates, and polystyrene, contained in tablets or capsules. When this hydrocarbon system exposed to gastric fluid, the hydrocarbon system hydrates and forms colloidal gel barriers around the surface of the gel. The air trapped by the inflated polymer has a lower density than unity and limits buoyancy in these DFs [25].

Microporous compartment system

The technique is based on encapsulation of the drug store inside a microporous compartment, with an aperture along its top and bottom walls. The peripheral walls of the drug's reservoir compartment are completely sealed to prevent any direct contact of the gastric mucosal surface with the odorless drug. The flotation chamber in the stomach, which contains diffused air, floats above the gastric contents for the improved efficiency of drug delivery system. The gastric fluid enters through the pores; the drug dissolves and carries the dissolved drug for continuous transport into the intestine for absorption.

\section{Alginate beads}

Several units of floating dose forms have been developed from freezedried calcium alginate. Spherical beads with a diameter of about 2.5 $\mathrm{mm}$ can be prepared by leaving sodium alginate solution in an aqueous solution of calcium chloride, which causes precipitation of calcium alginate. The beads are then separated and solidified in liquid nitrogen and freeze-dried $-24 \mathrm{~h}$ for $40^{\circ}$, which leads to the formation of a porous system that can maintain floating power above $12 \mathrm{~h}$.

Hollow floating microsphere

Floating microspheres are GRDDS based on the non-effervescent approach. Hollow microspheres (micro-balloons) are, in a strict sense, spherical empty particles without a core. These microspheres 
are typically free-flowing powders contains proteins or synthetic polymers, ideally $<200 \mu \mathrm{m}$ in size. Solid biodegradable microspheres involving a drug dispersed or dissolved during the particle-matrix can control drugs. Gastroretentive floating microcephases are lowdensity systems with sufficient buoyancy to float on gastric contents and remain in the stomach for a long time. As the system floats on the gastric contents, the drug is slowly released at the desired rate resulting in an increase in gastric retention with less fluctuation in plasma drug concentration [26].

\section{Advantages of floating microspheres}

- Enhanced bioavailability

- Enhanced first-pass biotransformation

- Sustained drug delivery/reduced frequency of dosing

- Targeted therapy for local ailments in the upper GIT

- Reduced fluctuations of drug concentration

- Improved receptor activation selectivity

- Reduced counter-activity of the body

- Extended time over critical (effective) concentration

- Minimized adverse activity at the colon

- Site-specific drug delivery

- Less inter- and intra-subject variability

- Minimizes the counter activity of the body leading to higher drug efficiency

- Fluctuations in drug concentration are minimized. Therefore, concentration-dependent adverse effects can be reduced

- Sustained mode of drug release enables the extension of the time over a critical concentration and thus enhances the pharmacological effects and improves the clinical outcomes

- Flexibility in DF design

- Extend patent protection, globalize products, and provide new business opportunities [19-22]

\section{Disadvantages of floating microspheres}

- These systems require a high level of fluid in the stomach for drug delivery so that they can float and work efficiently

- Not suitable for drugs that have solubility or stability problems in GIT

- If drugs such as nifedipine that is well absorbed with the entire GIT and which undergoes metabolism first, may not be desirable

- Drugs that are irritating to gastric mucosa also not suitable

- Acid intoxicants that are unstable in the acidic environment of the stomach are not suitable candidates for inclusion in the system

- The DF should be administered with a full glass of water (200-250 ml)

- These systems are no more beneficial than conventional DFs for drugs that are absorbed into the GIT $[27,28]$.

\section{METHOD OF PREPARATION OF FLOATING MICROSPHERE}

The following methods are used for the preparation of a floating microparticulate drug delivery system.

- Emulsion solvent evaporation technique

- Emulsion cross-linking technique

- Emulsion-solvent diffusion technique

- Emulsification heat stabilizing technique

- Multiple emulsion methods

- Coacervation phase separation technique

- Thermal change

- Non-solvent addition

- Polymer addition

- Salt addition

- Polymer-polymer interaction

- Spray drying technique

- Polymerization technique

- Normal polymerization

- Interfacial polymerization

- Ionic gelation technique

- Hydroxyl appetite (HAP) microspheres in sphere morphology

- Hot melt microencapsulation technique.

\section{EMULSION SOLVENT EVAPORATION TECHNIQUE}

The coating polymer is dissolved in an organic solvent that is incompatible with the liquid production vehicle. The main material (a water-soluble or insoluble substance in water) dissolves or disperses in the coating phase with agitation. The above solution is spread over the phase of the liquid production vehicle to obtain the appropriately sized microcapsules. If the mixture is heated to evaporate the solvent, the polymer shrinks around the core and this process is described in Fig. 8, if the core material coating dissolves in the polymer solution, the matrix type microcapsules will be formed $[25,26]$.

\section{EMULSION CROSS-LINKING TECHNIQUE}

This method is used for microparticles of natural carriers. The natural polymer dissolves in an aqueous medium and then a nonaqueous medium is added. The drug is dissolved in an aqueous solution of a gelatin carrier that has previously been heated to $40^{\circ} \mathrm{C}$ for $1 \mathrm{~h}$. The resulting solution is added dropwise in the oil phase, such as liquid paraffin, with a suitable surfactant at a stirring speed of $1500 \mathrm{rpm}$ for $10 \mathrm{~min}$ at $3^{\circ} \mathrm{C}$. Stir the resulting W/O emulsion again for $10 \mathrm{~min}$ at $15^{\circ} \mathrm{C}$. The microspheres are washed with suitable organic solvents such as acetone and isopropyl alcohol and dried in air. The formed microspheres are dispersed in $5 \mathrm{ml}$ of aqueous

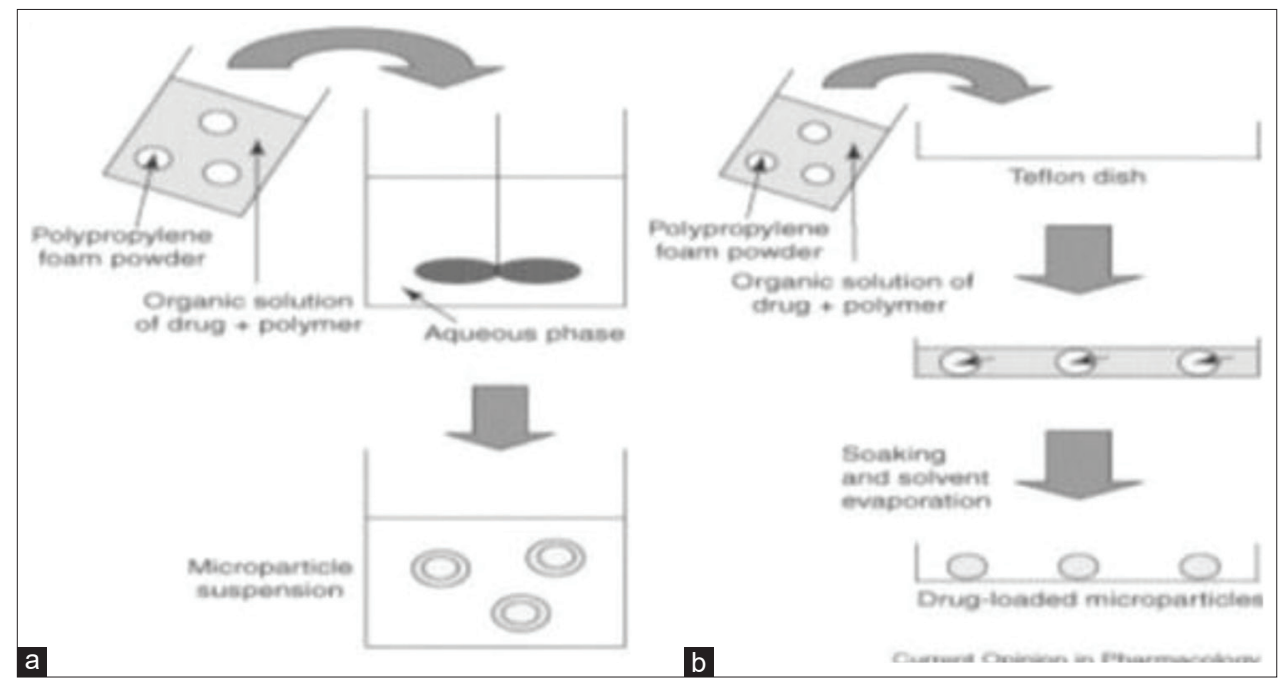

Fig. 8: (a and b) Emulsion solvent evaporation technique [29] 


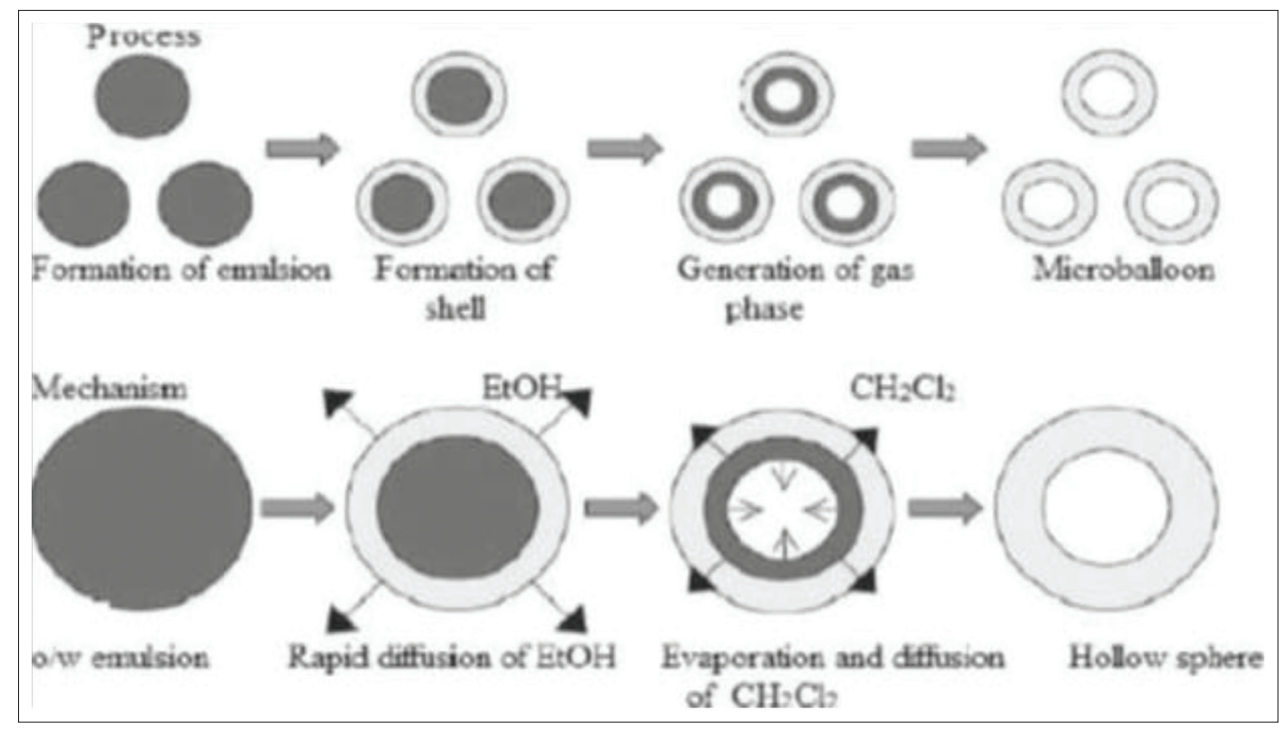

Fig. 9: Emulsion-solvent diffusion technique [32]

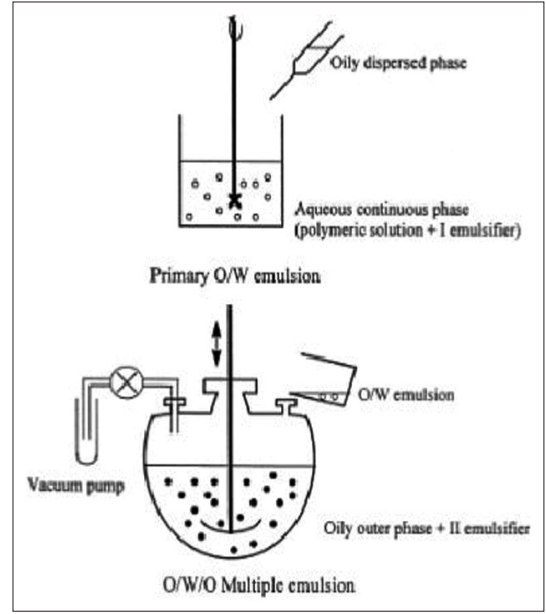

Fig. 10: preparation of microspheres by multiple emulsion technique [35]

glutaraldehyde saturated toluene solution at room temperature for $3 \mathrm{~h}$ and then cross-linked, further treated with $100 \mathrm{ml}$ of $10 \mathrm{~mm}$ glycine solution containing $0.1 \% \mathrm{w} / \mathrm{v}$ of tween 80 at $37^{\circ} \mathrm{C}$ for $10 \mathrm{~min}$ to stop the cross-linking. The main disadvantage of this method is excessive exposure to active ingredients in chemicals when they are added at the time of preparation and then centrifuged, washed, and separated. Natural surfactants used to stabilize the emulsion phase can greatly affect the size, size distribution, surface morphology, loading, drug release, and biological performance of the final multiparticulate product [30].

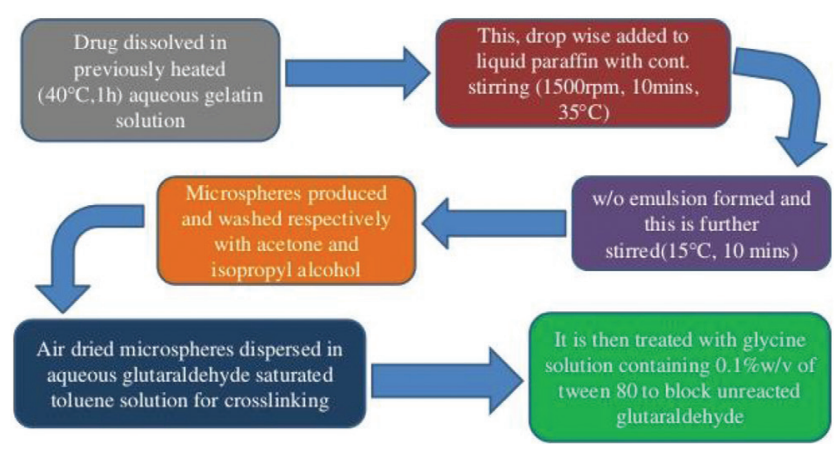

\section{EMULSION-SOLVENT DIFFUSION TECHNIQUE}

In this method Fig. 9, the drug is first dissolved in ethanol and dichloromethane (DCM) in a suitable polymer solution. This pharmaceutical polymer solution is added to a sodium lauryl sulfate solution, which is stirred for $1 \mathrm{~h}$ at $150 \mathrm{rpm}$ at room temperature by a propeller-type agitator, washed, and dried in a desiccator at room temperature goes. Floating microspheres prepared by this method have improved residence time in Colone [31].

\section{Emulsion heat stabilizing technique}

The aqueous polymer solution is prepared by dissolving polymer such as egg albumin in water in the presence of surfactants such as Tween 80 by mechanical stirring for $30 \mathrm{~min}$. Similarly, the oil phase is prepared by mixing $20 \mathrm{ml}$ of suitable oil and $5 \mathrm{ml}$ of diethyl ether with $1 \%$ span 80 (as an emulsifier) by magnetic stirring. The further oil phase is added to the aqueous phase by stirring at $800-1000 \mathrm{rpm}$ for $30 \mathrm{~min}$. The above primary emulsion is added to preheated $\left(65-70^{\circ} \mathrm{C}\right)$ oil by passing through the needle (No. 21) and stirred at $1000-1200 \mathrm{rpm}$ for $2 \mathrm{~h}$ till the solidification of microspheres takes place. The resulted microsphere suspension is cooled to room temperature by magnetic stirring. Then, $100 \mathrm{ml}$ of anhydrous ether is added. The above suspension is centrifuged for $15 \mathrm{~min}$, washed with ether to remove oily trace. The obtained microspheres are then dried in vacuum desiccators overnight and stored at $4^{\circ} \mathrm{C}$ in the dark [33].

\section{Single emulsion technique}

The microsphere of the natural polymer was prepared by the single emulsion technique. Natural polymers are dissolved in an aqueous medium followed by dispersion in a non-aqueous medium such as oil. In the next step, the cross-linking of the dispersed globules is performed using a chemical cross-linking agent or with the aid of heat. Glutaraldehyde and formaldehyde are used as chemical cross-linking agents.

\section{Multiple emulsion method}

This method Fig. 10 is suitable for water-soluble drugs such as proteins and peptides. The primary emulsion, o/w type, is prepared by dissolving an emulsifier containing a drug in an aqueous protein solution. The dispersed phase, which consists of the lipophilic organic phase, is added to it. The obtained primary emulsion is then subjected to homogenization by the addition of an aqueous solution of polyvinyl alcohol, resulting in a double emulsion. It is then subjected to evaporation solution [34]. 


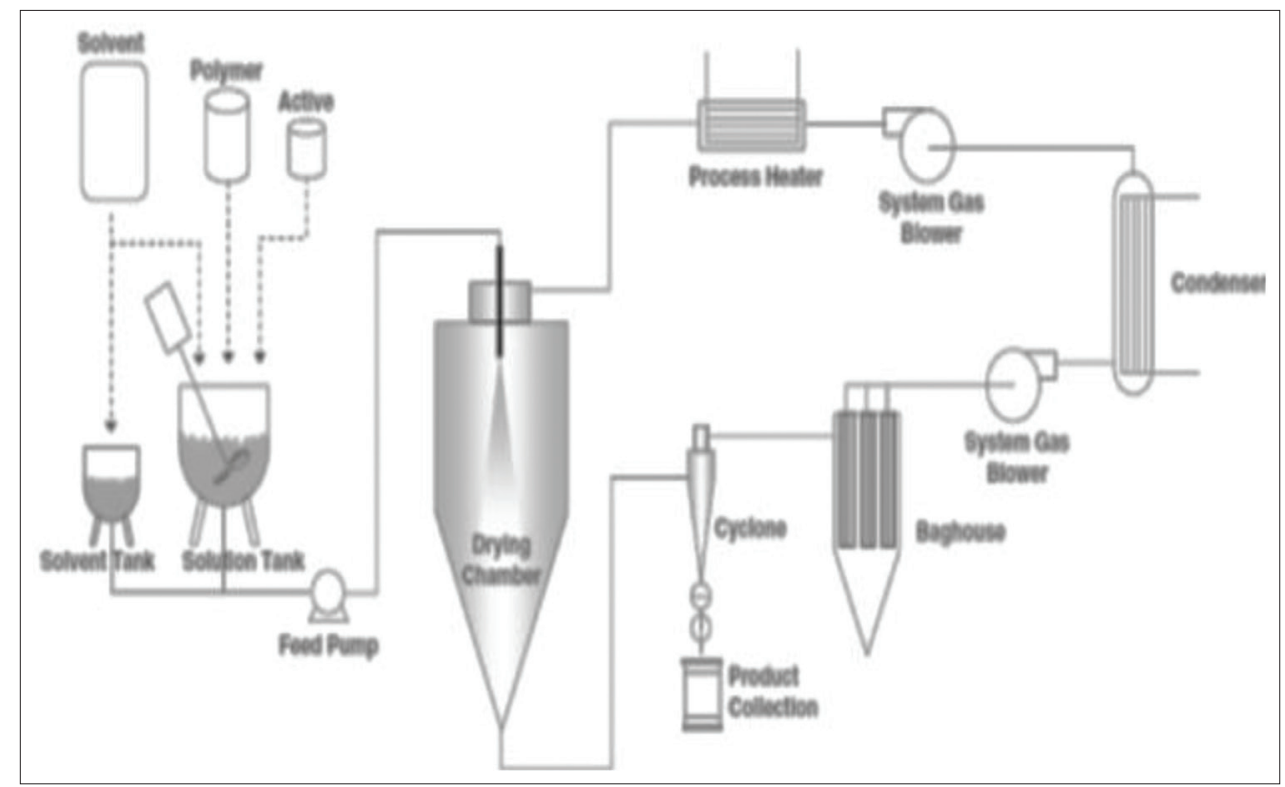

Fig. 11: Spray drying technique [39]

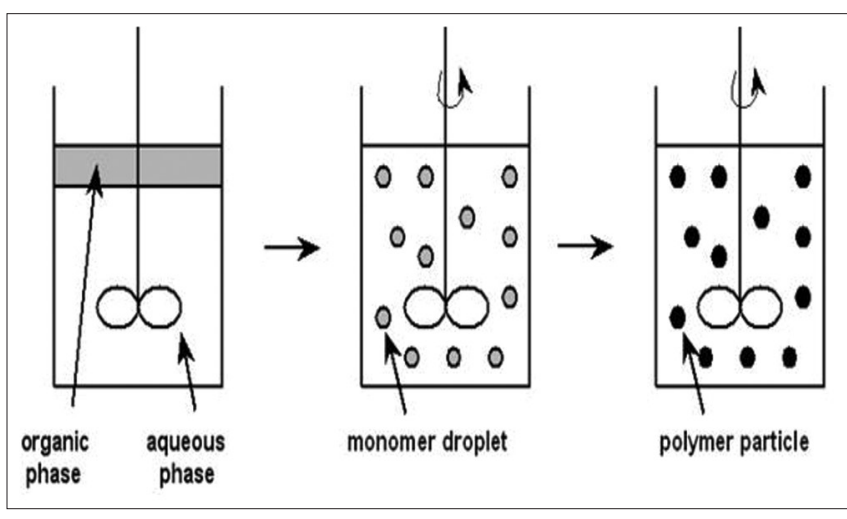

Fig. 12: Suspension polymerization

\section{Coacervation phase separation technique}

This process mainly involves the following steps:

- Step-1: The core material is dispersed in a coating polymer solution

- Step-2: The coating is accomplished by controlled physical mixing of coating solution and core material in the liquid manufacturing vehicle phase

- Step-3: Hardening of coating polymer in the following ways-

\section{Thermal change}

The polymer is dissolved in cyclohexane by vigorous stirring at $80^{\circ} \mathrm{C}$. The drug is added to the above solution with constant stimulation. The microsphere is obtained reducing the temperature by keeping in the ice bath. The product is washed twice with cyclohexane and airdried.

\section{Non-solvent addition}

Initially, the polymer is dissolved in toluene containing polyisobutylene in closure and shaken for $6 \mathrm{~h}$ at $500 \mathrm{rpm}$ and the drug is discrete. The resulting solution is added to benzene with constant excitation. The microcapsules are washed with $\mathrm{n}$-hexane and air-dried for $2 \mathrm{~h}$.

\section{Polymer addition}

The microspheres are formed by dissolving polymer (ethylcellulose) in toluene, methylene blue is added as core material. Coacervation is accomplished by the addition of liquid polybutadiene. The polymer coating is strengthened by adding a non-solvent (hexane). The resulting product is washed and air-dried.

\section{Salt addition}

An oil-soluble vitamin is dissolved in corn oil and mixed in a gelatin solution at $50^{\circ} \mathrm{C}$. Coacervation is done by adding sodium sulfate, resulting in a uniform coating of gelatin. Microspheres are collected and washed, cooled, and dried.

Polymer-polymer interaction

In this process, a homogeneous polymer solution is obtained by mixing an aqueous solution of an equal amount of gum arabica and gelatin (isoelectric point 8.9). The above solution is diluted twice with their volume of water, adjusted to $\mathrm{pH} 4.5$, and heated to $40-45^{\circ} \mathrm{C}$. Paradoxically charged macromolecules interact with these conditions and undergo coacervation. The liquid core material is added to the polymer solution and shaken well while maintaining the warm temperature. The mixture is then cooled to $25^{\circ} \mathrm{C}$ and the coating is hardened by cooling the mixture to $10^{\circ} \mathrm{C}[36,37]$.

\section{An aqueous or organic solution of polymer

$$
\text { Drug is added }
$$ \\ The drug is dissolved in the polymer solution}

Phase separation is carried out

$$
\text { Polymer rich globules }
$$

Hardening

$$
\checkmark
$$

Microsphere in an aqueous or organic phase

$$
\text { Separation, washing, and drying }
$$

\section{Spray drying technique}

The polymer is dissolved in a suitable volatile organic solvent such as DCM and acetone Fig. 11. The drug is added to the polymer solution under high-speed homogenization. The atomization of upward dispersion in a hot air stream leads to the formation of small droplets or fine mist. The solvent evaporates rapidly, forming microspheres of size range 1-100 $\mu \mathrm{m}$. The microspheres are separated from the hot air 


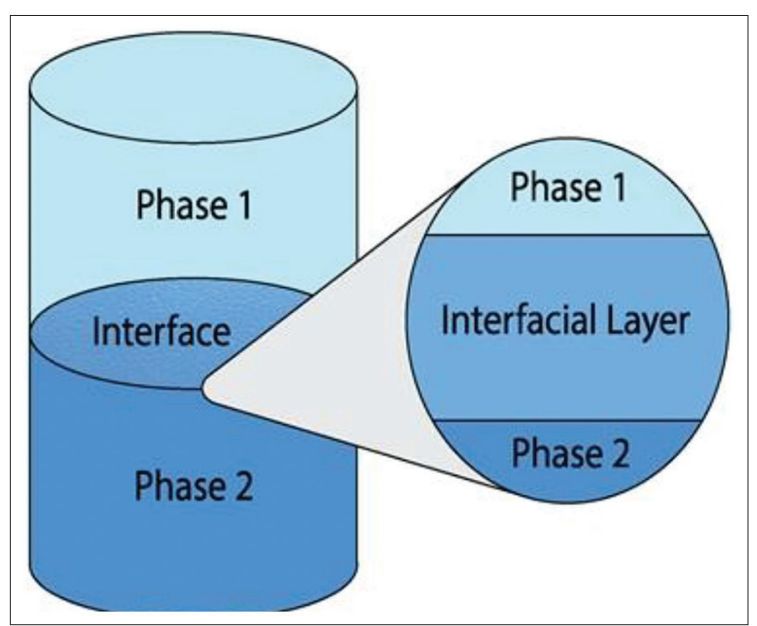

Fig. 13: Interfacial polymerization [40]

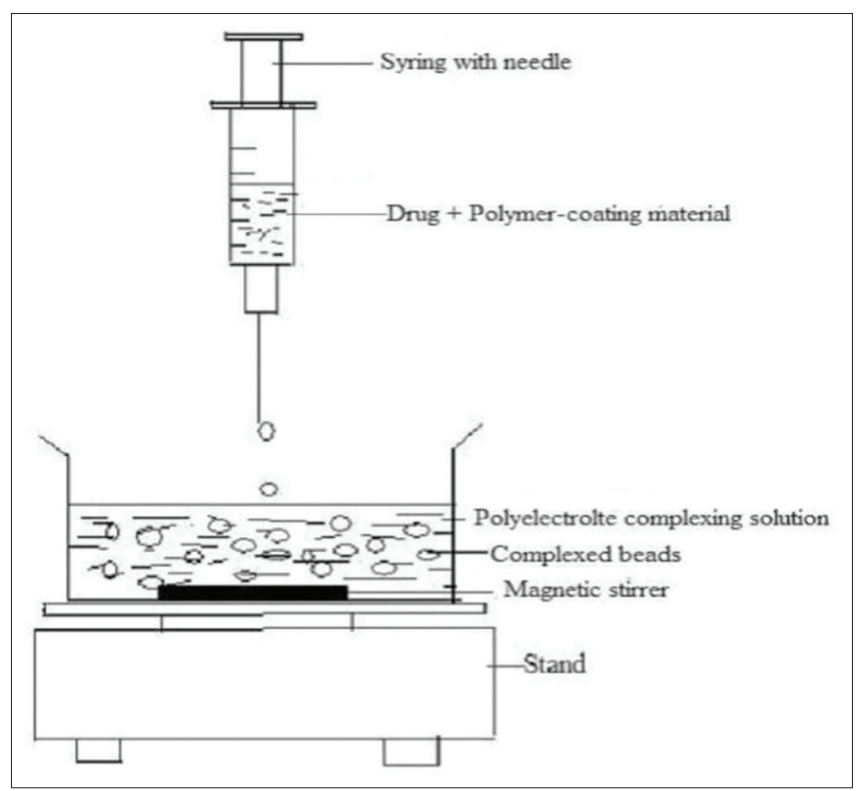

Fig.14: Ionic-gelation technique [41]

employing a cyclone separator. A major advantage of this procedure is the possibility of operation under aseptic conditions, leading to the formation of rapid and porous microparticles, which can be used for poorly soluble drugs $[38,39]$.

\section{Polymerization technique}

The polymerization technique mainly involves two methods-

- Normal polymerization

- Interfacial polymerization.

\section{Normal polymerization}

Normal polymerization classified as:

1. Bulk polymerization

2. Suspension/pearl polymerization

3. Emulsion polymerization.

\section{Bulk polymerization}

Polymerization is initiated by heating a monomer or a mixture of monomers as well as initiators or catalysts, drug is loaded simultaneously. Although it is a simple technique, it cannot be applied to thermolabile active ingredients.

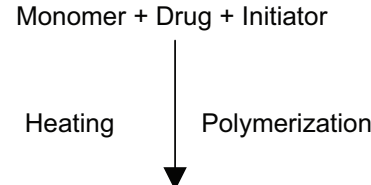

Polymer block

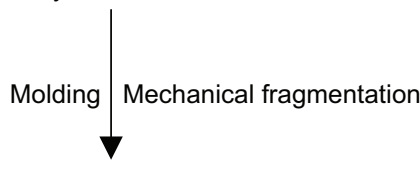

Microsphere

Suspension polymerization/Pearl polymerization

In this pearl polymerization method Fig. 12, the monomer mixture is heated at lower temperatures than the polymerization, with an active drug as droplet dispersion in continuously in the aqueous phase. Particle size microspheres are usually $<100 \mu \mathrm{m}$. Emulsion polymerization is carried out in the presence of an initiator in the aqueous phase at low temperature in suspension form. The outer phase usually consists of water through which heat can be easily dissipated. The formation of high polymer is possible by these techniques, but sometimes the polymer can be combined with non-reactive monomers and other additives.

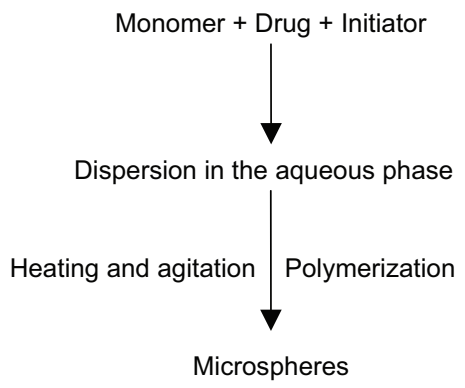

Interfacial polymerization

It involves the reaction of various monomers at the interface between the two immersed liquid phases to form a film of the polymer that essentially covers the dispersed phase. Two reactive monomers are employed in this technique; one dissolved in the continuous phase while, others dispersed in the continuous phase (aqueous), during which another monomer is emulsified (Fig. 13) $[39,40]$.

\section{Ionic gelation technique}

This technique has been used successfully by low-density polymers and gasproducing agents such as tartaric acid and citric acid. The polymer solution of an aqueous solution is prepared by dissolving the polymer in water. The main material which is finely sieved (sieve No. 120) is added to the polymer solution and mixed to form a smooth viscous dispersion. This dispersion is added drop wise into through a $0.55 \mathrm{~mm}$ diameter fine needle syringe $10 \% \mathrm{w} / \mathrm{v} \mathrm{CaCl}_{2}$ solution. It is treated by stirring for $15 \mathrm{~min}$ at $200 \mathrm{rpm}$ resulting in a spherical rigid microsphere. Finally, the microspheres are collected and dried in an oven at a temperature of $45^{\circ} \mathrm{C}$ for $12 \mathrm{~h}$ Fig. 14 [41].

\section{HAP microspheres in sphere morphology}

The HAP granules used in this process are obtained by the method of precipitation, followed by a spray drying process. The first microspheres are prepared by an emulsion of oil-in-water, followed by solvent evaporation technique. The oil-in-water emulsion obtained by dispersing in the organic phase (DCM solution containing $5 \%$ of Ethylene-vinyl acetate) and the appropriate amount of HAP in an aqueous medium of surfactant. When dispersed in the aqueous phase, the organic phase is turning into small droplets and each droplet is surrounded by surfactant molecules. Thus, a protective layer is formed 


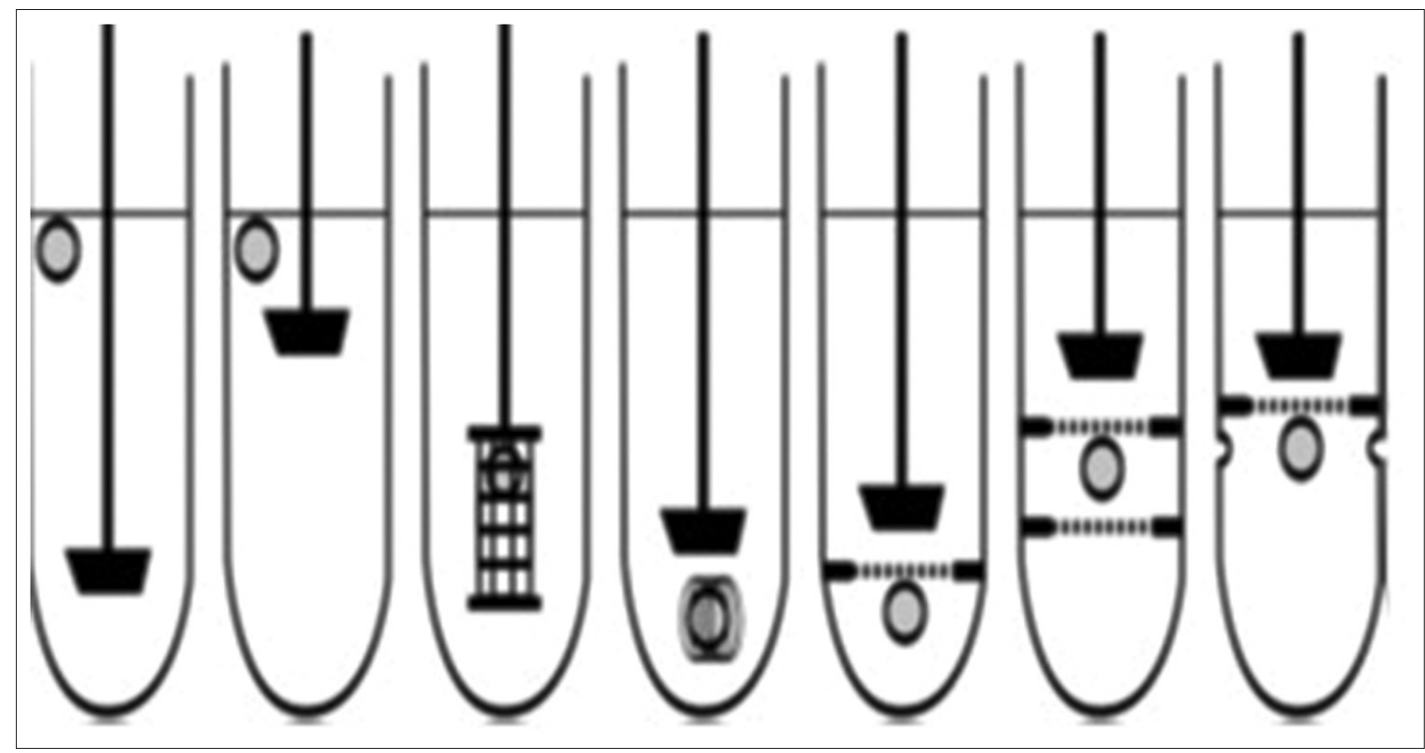

Fig. 15: Compendia dissolution apparatus and modifications [45]

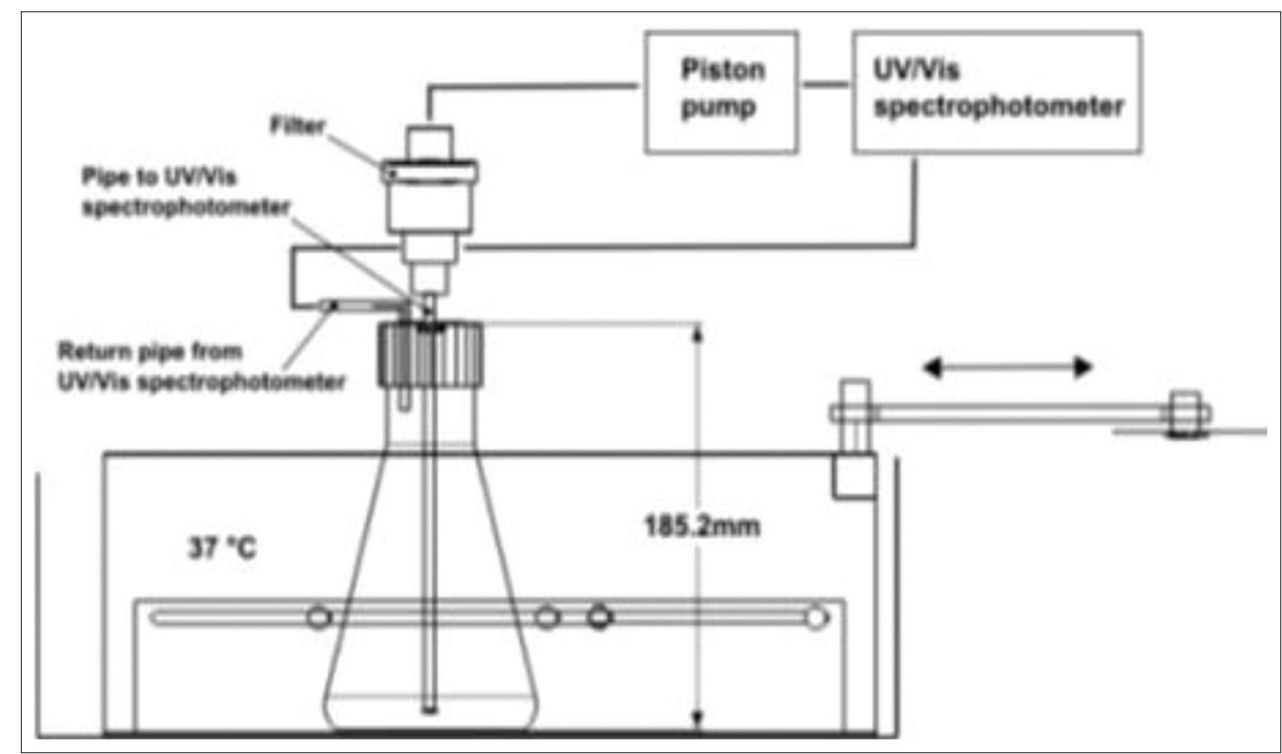

Fig. 16: Schematic of the "custom-built stomach model" [53]

on the surface that prevents the droplets from coalescing and helps individual droplets to remain. While stirring, DCM slowly evaporates from the droplets and after the complete removal of DCM, the droplets harden to become individual microspheres. The size of droplets formed depends on many factors such as types and concentration of stabilizing agents and type and speed of stirring employed, which in turn affects the size of the final microspheres formed [42].

\section{Hot melt microencapsulation technique}

In this method, the polymer is melted and then mixed with the solid particles of the drug which has been sieved to $<50 \mu \mathrm{m}$. The mixture is suspended by continuous stirring in a non-soluble solvent such as silicone oil and heated to $5^{\circ} \mathrm{C}$ above the polymer's melting point. Once the emulsion has stabilized, it cools until the solid particles freeze. The resulting microspheres are washed by decay with petroleum ether. This method is suitable for the water labile polymers, for example, poly anhydrides. Microspheres with a diameter of $1-1000 \mu \mathrm{m}$ can be obtained. Particle size can be distorted by changing the stirring speed. The only disadvantage of this method is the moderate temperature at which the drug is exposed [43].

\section{CHARACTERIZATION OF GASTRORETENTIVE DFS}

At present, clinical studies with humans are still the gold standard for investigating the function of new gastroretentive systems. Due to the high costs caused by in vivo studies as well as various disadvantages affecting the interpretation of in vivo data, powerful in vitro methods are needed for the initial evaluation of the behavior of new gastroretentive concepts. The following sections provide an overview of the most frequently used in vitro methods and will enable the reader to critically evaluate data obtained with these methods (Fig. 15-17).

In vitro and in vivo methods to characterize GRDF, the probe can be divided into the following groups based on the parameter:

- In vitro assessment of drug release behavior

- In vivo assessment of gastroretentive properties.

In vitro assessment of drug release behavior

One of the most widely studied parameters of GRDFs is their drug release behavior, preferably in biorelevant conditions. However, the 


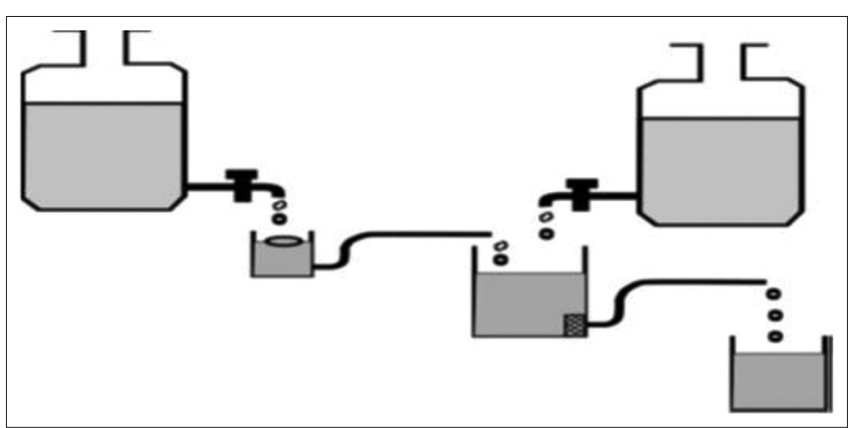

Fig. 17: Schematic of the multicompartment dissolution apparatus [50]

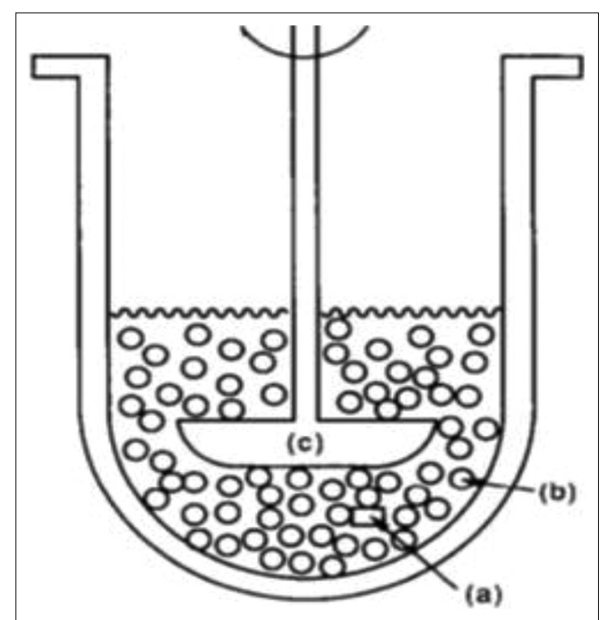

Fig. 18: Schematic of the paddle-bead method [54]

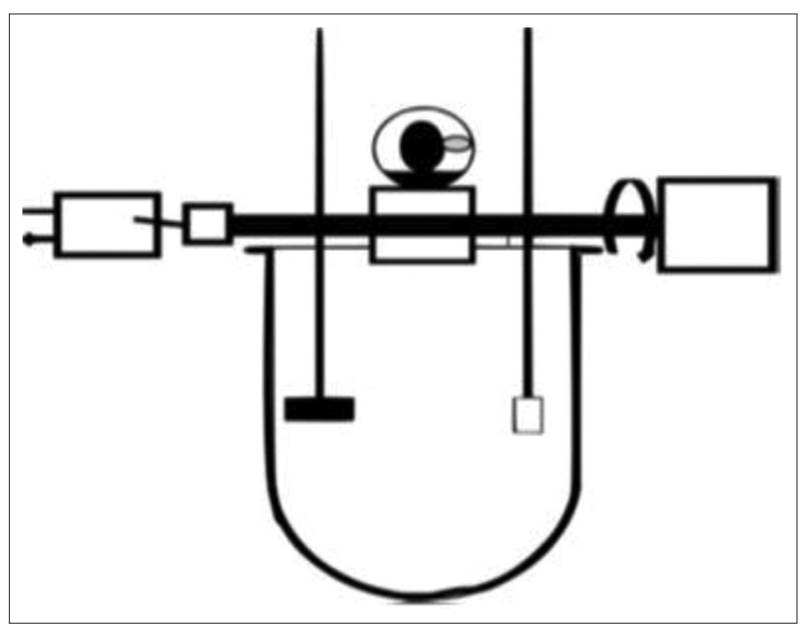

Fig. 19: Schematic of the dissolution stress test device [56]

poorly anticipated backlog in vivo drug release is one of the most abandoned facts in this regard. Interestingly, the majority of scientists rely on compendial dissolution test apparatuses, which is generally applicable to the investigation of drug release from oral DFs. However, it is commonly accepted that gastric conditions have a sharp effect on drug release behavior, even for normal oral DFs. Considering the physiological condition in the human stomach, mandatory methods are best applied for quality control purposes but are generally not suitable for studying the drug release of GRDFs [39,40]. Nevertheless, devices such as the rotating basket or the paddle apparatus, as well as simple modifications of these tools are widely applied to GRDFs testing [44,47]. It is clear that the outcome of such tests largely depends on the type
Apparatus shown in Fig. 15-19 of GRDF examined. In particular, for low-density and, thus, floating GRDF, dissolution testing in computer evaluation can be problematic, as the relatively large surface area of the system is not exposed to the dissolution medium [46]. Several methods have been suggested to interrupt the flotation of oral DFs during dissolution testing. Helical wire sinks are the easiest and most widely accepted process to use [48]. However, when examining floating and at the same time checking the expansion system, the use of a sinker may interfere with the swelling behavior of the DF [45]. An alternative is to have a floating system under the ring mesh.

Pillay et al. and Durig et al. proposed a setup in which they introduced one and two stainless steel ring meshes, respectively, in the paddle apparatus $[46,49]$. The purpose of this study was to produce more reproducible data. However, these methods are far from physical conditions.

Another very simple approach was recently demonstrated by Kong et al. [50] who used a shaker incubator at a temperature of $37^{\circ} \mathrm{C}$ at $100 \mathrm{rpm}$. At the specified time point, samples were taken and the medium was changed.

Eberle et al. suggested a similar approach and referred to it as a "custom-built stomach model." With this device, they tried to stick the DF to the paddle shaft and avoid constant contact with air. It consists of Erlenmeyer flasks, filled with $400 \mathrm{ml}$ of medium and fixed in a water-bath shaker [51]. Overall, this setup released the apparent acceleration drug of a test floating system compared to a simple USP II paddle equipment setup. However, it has to be kept in mind that, in the paddle system, the DF was able to freely hover over the medium surface. In this region, the shear stress is low, which gives a good insight into the obtained results $[52,53]$. The artificial nature of this setup may allow for more fertile measurements but, presumably, it will not be reflected in in-vivo behavior due to lack of physiological relevance.

Parikh et al. [54] identified the $\mathrm{pH}$ difference of the GIT as a major issue that should occur in the dissolution test of GRDF in combination with particularly weak basic drugs. Based on the Rosette-Rice apparatus, they created a multi-compartment transfer model consisting of a gastric, a bowel, and an absorption compartment. In this device, the drug is freely transferred from the gastric to the intestinal compartment, while the absorption and intestinal compartment are separated by a filter membrane. The $\mathrm{pH}$ of the media can be adjusted through reservoirs containing $1 \mathrm{~N} \mathrm{HCl}$ or borate buffer. Demonstrated potential benefits of an in-vitro system for a controlled release floating system compared to immediate-release tablets $[47,54]$. However, the in vitro dissolution and absorption profile may have also observed for a similar, non-floating controlled release system.

In contrast to the floating dose form, drug release testing of mucoadhesive systems using complex dissolution test methods seems less complicated. Therefore, in many cases, a paddle tool and a rotating basket tool are used for this purpose. However, since mucoadhesive systems are designed to adhere to the gastric mucosa, it would be misleading to study drug release if the dissolution medium is in full contact with the entire surface. Consequently, drug release can be extremely surprising. In a study by Llabot $e t$ al., cyanoacrylate glue was used to fix one side of the monolithic system in the metal discs tested during disruptive experiments [55].

A step toward further physiological dissolution test of novel GRDFs was made by Nakagawa et al. [56], using a modified version of the USP II paddle apparatus proposed by Aoki et al. In this model, the dissolution vessels of the paddle apparatus are filled with a polystyrol beads to mimic physiological stress in the stomach $[57,58]$. Nakagawa et al. applied this device to a novel GRDF and showed that one of the tested aggregates did not release the drug due to a lack of mechanical strength [62]. 
Similar observations were recently made using a so-called dissolution stress test device [59]. This device was developed by Garbacz et al. [56] and uses an inflatable balloon to bring real pressures on DFs. By applying postprandial SmartPill data, we were able to simulate extensive gastric pressure profiles as they occur in vivo. After examining the drug release behavior of marketed gastroprotective DFs, it can be seen that no system was able to withstand these stresses [60]. These data suggested that significant pressure sensitivity is one of the major issues to consider during the development of novel GRDFs. In addition to drug release behavior, gastroretentive properties are also endangered by intragastric stresses, even in postnatal conditions.

The mechanism of drug release from swellable matrices is determined by several physico-chemical phenomena. Among them, polymer water uptake, gel layer formation and polymeric chain relaxation are currently regarded as primarily involved in the modulation of drug release [61]. In addition to dissolution stress testing tools, there have been recent developments toward more physically relevant coherent testing of DFs. In vitro models to simulate gastric physiology include TNO's TIM-1 system, human gastric simulator, and dynamic gastric model [51,52]. However, none of them have yet been used for drug release testing of GRDFs, but most of them have the potential to characterize such systems in a relevant manner.

\section{Drug-excipients interaction studies}

Assessment of possible incompatibilities between an active drug substance and different excipients forms an important part of the preformulation stage during the development of solid dosage forms [61]. Fourier Transform Inferred (FTIR) spectroscopy was carried out to check the compatibility between drug and polymer. The excipients used were HPMC K4M, HPMC K15M, and Ethyl cellulose [63].

\section{Stirring rate}

To observe the effect of movement speed on the size of the resulting microspheres, formulations on different movement speeds; $300 \mathrm{rpm}$, $500 \mathrm{rpm}$, and $100 \mathrm{rpm}$. The size of the resulting microspheres decreased within creasing agitation, but the increase was not statistically significant. It can be speculated that the movement speed was not able to break the effects of the stirring rate on microsphere prepolymer into finer droplets during the study [64].

\section{Temperature of preparation}

Sato et al. have studied the optimum preparation temperature concerning the microsphere cavity formation. The solution drug and polymer were poured into an aqueous solution of polyvinyl alcohol at various temperatures, that is, $20,30,40$, and $50^{\circ} \mathrm{C}$. They concluded that preparation at 20 or $30^{\circ} \mathrm{C}$ provided perforated microspheres, which are high pores along the surface that crumble when touched. Although the corresponding apparent particle densities of the resulting hollow microspheres were low, both buoyancies were low, probably due to easy penetration of the dissolution medium through the porous surface [65].

\section{Plasticizers}

Plasticizer concentration affects the rate of release of drug from the surface of microspheres. They have found that the addition of plasticizer makes the material wall more elastic and flexible so that it never brittle or broken under pressure. It was also observed that drug release increased significantly with the increasing concentration of plasticizer [66].

\section{The volume of the aqueous phase}

Use of various volumes affects formation of hollow microspheres. He observed that the potential advantage of using large volumes of the external aqueous phase was the lack of necessary stirring time. The solubility of DCM in water is $1 \% \mathrm{w} / \mathrm{v}$. Diffusion of DCM, using a large volume (400-500 ml) compared to the volume of $200 \mathrm{ml}$, the aqueous phase, and hence the freezing of particles, occurred faster [67]

\section{In vivo assessment of gastroretentive properties}

To provide evidence of in vivo efficacy of GRDDS, an in vivo study is requires a well-designed animal model or humans. In vivo studies provide information about the GRT and bioavailability of the drug. The first requirement is to select an animal model for a successful in vivo study. For example, in small animals such as mice, rats, guinea pigs, and rabbits, there may be an issue dealing with animals, especially for large DFs [68,69]. As a result, measurements of the GRT and bioavailability are still difficult [70].

Therefore, most of the works of literature on the formulation of GRDDS showed evidence of in vivo gastric retention in relatively large size animals such as dog or human as well as in vitro characterization studies such as dissolution study, estimation of floating lag time, and floating duration [71]. In vivo gastric retention was hypothesized that GRDDS would provide superior therapeutic efficacy over conventional DF. Several sophisticated visualization techniques are helpful in this regard. Gamma scintigraphy is one such popular and elegant technique for proper evaluation of gastroretentivity in humans [72]. A small amount of radioisotope with a short half-life is included in the DF. The formulation has come into a neutron source, which allows it to release the captured gamma rays as an image after being processed by a computer $[73,74]$.

Badve et al. [75] fabricated hollow calcium pectinate beads of diclofenac sodium for its chronopharmacological action. The floating beads were structurally hollow spheres with a bulk density of $<1 \mathrm{~g} / \mathrm{ml}$ and a porosity of $34 \%$. An in vivo study on rabbits was performed by gamma scintigraphy showing gastroretention of beads up to $5 \mathrm{~h}$. There have been several other recent reports of success in vivo gastric retention of floating tablets and microspheres containing versatile drug molecules such as ascaridole, calcium-disodium edentate, and repaglinide [76,77]. Magnetic resonance imaging is another technique to prove in vivo gastroretention of a GRDDS. This is a relatively safe technique that uses magnetic fields and radio waves to visualize the entire anatomical structure with the location of the entire DF [78]. Compounds with superparamagnetic properties (such as ferrous oxide) are included for visualization [79].

Steingoetter et al. [80] used this technique to report the in vivo gastric retention of $\mathrm{Fe}_{3} \mathrm{O}_{4}$ containing gadolinium chelates (Gd-DOTA) as a superparamagnetic agent and in analyzing intra-gastric tablet status and residence time in human volunteers were successful. Radiology or X-ray is another alternative technique where a radio-opaque material with the GRDDS is included. This technique has been noted in the evaluation of gastroretentivity, the rate of disintegration of DFs, and their esophageal transit [81]. To diagnose and monitor the GIT, gastroscopy is another commonly used technique. This technique uses fiber optics or a video system to detect DF. Since this procedure is less convenient, it is sometimes used to assess gastric retention in any DF in humans with minor anesthesia [82]. However, in the case of dogs, complete anesthesia is required, as reported by Dhiman et al. [79].

\section{Animal study}

Klausner et al. [83] developed a novel controlled release GRDDS of Levodopa using polymeric membranes with extended dimensions and high stiffness. In vivo studies were performed with the beagle dogs treated with carbidopa. The developed formulation was administered and the location of the DF in the GIT was determined by the X-ray. Furthermore, serial blood samples were taken for active medicine and tested. It has been revealed that the optimized controlled release of Levodopa GRDDS can maintain therapeutic concentrations of levodopa (>500 ng/ml) above $9 \mathrm{~h}$. The average absorption time was much longer than non-GR controlled release-particles and oral solution.

Jain et al. [67] a floating microsphere of repaglinide (hypoglycemic agent) is formed, where calcium silicate was used as a porous carrier and Eudragit as polymer. Sprague-Dawley male rats were subjected to organ distribution studios and suspension of $99 \mathrm{mTc}$-labeled floating microspheres was given orally with water to albino rabbits. After $6 \mathrm{~h}$ of 
gastric residence times, confirmed by gamma scintigraphy, rats were sacrificed and organs separated (abdominal and intestinal region). The organ distribution of the test compound was found to be uniform and the associated bioavailability was 3.17 times higher than the marketed tablets.

In vivo, anti-tumor studies were conducted by Shishu and Aggarwal [84] to investigate the therapeutic efficacy of 5-fluorouracil of floating calcium alginate beads. It was found that the multiple-unit floating system was able to reduce the incidence of gastric tumors in mice by $74 \%$, whereas as a conventional tablet dose, the reduction of this incidence was found to be only $25 \%$.

Pande et al. [85] prepared cefpodoxime proxetil microspheres as GRDDS. The solvent evaporation technique was used for the development of the drug-loaded microspheres, where ethyl cellulose and HPMC were used as release retarded materials. Two groups of male albino rats were subjected to oral ingestion of the cefpodoxime proxetil microspheres and cefpodoxime proxetil suspension at a dose of $10 \mathrm{mg} / \mathrm{kg}$. Blood samples were collected from the retro-orbital region at pre-determined time intervals and centrifuged to separate plasma samples that were eventually analyzed by HPTLC. This study increased the relative bioavailability of the drug, prepared in microspheres, which is 1.5 times higher than in suspension.

Khan and Dehghan [86] reported increased bioavailability of atorvastatin calcium, which is given in albino rabbits in the form of floating tablets. With an in vitro floating lag time of $56 \pm 4.16 \mathrm{~s}$ and a floating duration of $6 \mathrm{~h}$, tablets can increase bioavailability 1.6 times compared to conventional tablets.

The stomach is the main absorption site for cephalexin and gastroretentive formulation may achieve its increased bioavailability as confirmed by Yin et al. [87]. Cephalexin filled gastrofloating tablets were prepared by (HPMC K100M) as a matrix and sodium bicarbonate as a gas-forming agent. The developed tablets had a floating lag time of fewer than $15 \mathrm{~s}$ and a floating duration of more than $12 \mathrm{~h}$, with an in vitro survival sustained-release profile for $12 \mathrm{~h}$. In vivo, pharmacokinetic studies were conducted in fed and fasted beagle dogs compared with conventional capsules and sustained-release tablets. Cephalexin floating tablets resulted in relative bioavailability of $99.4 \%$ with an extended drug release profile, while reference formulations provided relative bioavailability of $39.3 \%$. However, the study showed a significant effect on the pharmacokinetics of sustained-release tablets.

The combination of floating and bioadhesive was found to provide an improvement in the in vivo efficacy of famotidine minitablets manufactured by Zhu et al. [88] with HPMC K4M as release retarding and swollen polymer with Carbopol 971P (bioadhesive materials) and sodium bicarbonate (gas-forming agent). Tested in rat models, the mini-tablets could result in a 1.62-fold increase in bioavailability.

Qi et al. [89] in vivo success of the compression coated floating tablet of ofloxacin has been noted. The tablets were prepared by hydroxypropyl cellulose as a compression coating agent, sodium alginate, as a drug release modifier, and sodium bicarbonate as an effervescent agent. In vitro characteristics of the tablets such as a floating lag time of $30 \mathrm{~s}$ and floating duration of $12 \mathrm{~h}$ were well correlated with its relative bioavailability of $172 \%$ compared to the market formulation studied in New Zealand rabbits.

The combination of effervescence and swelling floating mechanism as a means of improved gastroretentivity and in vivo efficacy was proved by Kadivar et al. [83] for imatinib mesylate sustained-release tablet prepared with HPMC K4M, sodium alginate, and Carbomer 934P. Studied in New Zealand rabbits, gastroretentive tablets can increase the bioavailability by about 1.5 times compared to the conventional tablets (Gleevec).

\section{Human study}

Chen et al. [90] developed a gastroretentive tablet based on swelling/ effervescence mechanism to administer the antihypertensive drug losartan with hydroxyethylcellulose, sodium carboxymethyl cellulose, and sodium bicarbonate. The tablets were found to float more than $16 \mathrm{~h}$ in vitro with swelling to $2 \mathrm{~cm}$ in diameter within 3 h. In addition, the tablets showed a $\mathrm{pH}$-dependent drug release with an extension of $24 \mathrm{~h}$. When tested in healthy human volunteers, the optimized tablets achieved increased bioavailability relative to the immediate release market formulation of approximately $164 \%$ of the Kozar ${ }^{\circledR}$ name. As expected, gastroretentive floating tablets produced favorable pharmacokinetic parameters: Maximum residence time and Tmax values were higher and Cmax values were lower than those of commercial formulation.

Bomma and Veerabrahma [91] established the efficacy of antibiotic treatment over traditional tablets, Zocef $®$, with gastroretentive tablets of cefuroxime axetil. Developed and optimized tablets were based on a combination of swelling (HPMC and Polyox WSR 303) and effervescence (citric acid and calcium carbonate) mechanism. With an in vitro floating duration of more than $12 \mathrm{~h}$ with a floating lag time of fewer than $30 \mathrm{~s}$, the optimized tablets can be retained $225 \pm 30$ min in human subjects as confirmed by in vivo radiographic studies. Identical tablets were tested on eight healthy human volunteers. Developed floating tablets showed better bioavailability than Zocef tablets. A significant difference was observed in $C \max , T \max , t 1 / 2, A U C 0-\infty$, based on in vivo performance, and mean residence time between test and reference $(p<0.05)$. Compared to the reference tablets, the floating tablets of cefuroxime axetil increased relative bioavailability 1.61 times.

The in vivo efficacy of GRDDS as an active drug containing a high weight of nicotinamide $(600 \mathrm{mg})$ was patented by Meijerink et al. [92]. Hypromellose was used as a swelling agent in that formulation. Eight healthy adult volunteers were used to ascertain their pharmacokinetic profiles. Blood samples as well as urine were collected at predetermined time intervals. The developed DF was able to maintain increased nicotinamide plasma levels in vivo for at least $8 \mathrm{~h}$ after ingestion by volunteers.

Ranade et al. studied ellagic acid and aloe vera gel powder as a bilayer floating tablet prepared with HPMC K15M and sodium bicarbonate to treat stomach ulcers. The researchers reported $75 \%$ ulcer blockage compared to $57 \%$ ulcer inhibition with ellagic acid alone. This efficacy was generated from tablets that appeared to have only a 4-h cumulative $92 \%$ drug release in the in vitro floating period [93]

In another study, the efficacy of gastroretentive emulsion gel calcium pectinate beads approached cinnarizine prepared by the ionotropic gelation method was established by Abouelatta et al. [94]. Researchers reported that the average in vivo efficacy with a mean AUCO-24 and $A U C 0-\infty$ improved, respectively, increased by 1.79 and 3.80 times, that of conventional tablets in healthy human volunteers. Interestingly, the beads composed of pectin (base), glyceryl monooleate, and labrafac lipophile WL 1349 (oil phase) have in vitro floating capacity.

\section{AUTHORS CONTRIBUTIONS OR CONFLICT OF INTERESTS}

All the authors have contributed equally. The author confirms that there are no conflicts of interest, financial, or otherwise.

\section{AUTHORS' FUNDING}

The author(s) received no financial support for the research, authorship, and/or publication of this article.

\section{REFERENCES}

1. Hafeez A, Maurya A, Singh J, Mittal A, Rana L. An overview of floating microsphere: Gastro retention floating drug delivery system. J Phytopharmacol 2013;2:1-12.

2. Awasthi R, Kulkarni GT. Decades of research in drug targeting to the upper gastrointestinal tract using gastro retention technologies: Where do we stand? Drug Deliv 2014;23:378-94.

3. Schneider F, Koziolek M, Weitschies W. In vitro and in vivo test methods 
for the evaluation of gastroretentive dosage forms. Pharmaceutics 2019;11:416.

4. Khori N, Naasani I, Iseki K, Miyazaki K. Improving the oral bioavailability of Sulpiride by the gastric-retained form in rabbits. J Pharm Pharmacol 1996;48:371-4.

5. Guyton AC. Movement of food through the alimentary tract. In: Human Physiology and Mechanisms of Disease. Vol. 3. London: W.B. Saunders Co.; 1982. p. 487-97

6. Helliwell M. The use of bioadhesive in targeted drug delivery within the gastrointestinal tract. Adv Drug Deliv Rev 1993;11:221-51.

7. Bansil R, Turner B. Mucin structure, aggregation, physiological functions, and biomedical applications. Curr Opin Colloid Interface Sci 2006;11:164-70.

8. Andrews GP, Laverty TP, Jones DS. Mucoadhesive polymeric platforms for controlled drug delivery. Eur J Pharm Biopharm 2009;71:505-18.

9. Danicla A, Giovanna M, Giulia B, Piera DM, Giovanni FP. Mucoadhesion dependence of pharmaceutical polymers on mucosa characteristics. Eur J Pharm Biopharm 2004;22:225-34

10. Singh BN, Kim KH. Floating drug deliverysystems: An approach to oral controlled drugdelivery via gastric retention. J Control Release 2000;63:235-59.

11. Chawla G, Gupta P, Koradia V, Bansal AK. Gastro retention: A means to address regional variability in intestinal drug absorption. Pharm Technol 2003;2003:50-2

12. Mishra SK, Gupta MK, Jain NK. Development and characterization of floating microspheres based drug delivery system for peptic ulcer. $\mathrm{J}$ Drug Deliv Ther 2018;8:155-62.

13. Badoni A, Ojha A, Gnanarajan G, Kothiyal P. Review on gastro retentive drug delivery system. Pharm Innov 2012;1:32-42.

14. Griffith GH, Owen GM, Kirkman S, Shields R. Measurement of the rate of gastric emptying using Chromium-51. Lancet 1996;1:1244-5.

15. Yadav A, Jain DK, Balekar N. Floating controlled drug delivery systems for prolonged gastric retention: A review. Pharm Res 2009;1:133-41.

16. Kavitha S, Peeyush KM, Anil B, Akanksha G, Navneet G. Floating microsphere as gastroretentive drug delivery systems. A review. World J Pharm Res 2015;4:668-84.

17. Manavalan S, Sarojini R. An overview of various approaches to gastroretentive dosage forms. Int J Drug Dev Res 2012;4:1-13.

18. Gholap SB, Banarjee SK, Gailkwad DD, Jadhav SL, Thorat RM. Hollow microsphere: A review. Int J Pharm Sci Rev Res 2010;1:74-9.

19. Dighe DA, Choudhary NH, Mangesh ST, Prasad RV, Manoj SK, Meera CS. Floating drug delivery system: A novel approach towards gastro retention. Int J Pharm Chem Sci 2012;1:1128-42.

20. Dutta P, Sruthi J, Patra N, Bhanoji R. Floating microspheres: Recent trends in the development of gastroretentive floating drug delivery system. Int J Pharm Sci Nanotechnol 2011;4:1296-306.

21. Babu SS, Suresh P, Khalilullah S, Nama S, Brahmaiah B, Desu PK. Gastroretentive drug delivery system a review. Int J Pharm Pract Drug Res 2013;3:26-31

22. Arora S, Alij AA. Floating drug delivery systems. A review. AAPS Pharm SciTech 2005;6:372-390.

23. Saxena A, Gaur K, Singh V, Singh RK, Dashora A. Floating microspheres as drug delivery system. Am J Pharm Pharm Sci 2014;1:27-36.

24. Vyas SP, Khar RK. Controlled Drug Delivery Concepts and Advances. $1^{\text {st }}$ ed. New Delhi: Vallabh Prakashan; 2012. p. 196-217.

25. Chawla G, Gupta P, Koradia V, Bansal AK. Gastroretention a means to address regional variability in intestinal drug absorption. Pharm Technol 2003;27:50-1.

26. Jyothi NV, Prasanna PM, Sakarkar SN, Prabha KS, Seetha P, Srawan RG. Microencapsulation techniques, factors influencing encapsulation efficiency. J Microencapsul 2010;27:187-97.

27. Jain NK. Progress Controlled and Novel Drug Delivery Systems. $1^{\text {st }}$ ed. New Delhi, Bangalore: CBS Publishers and Distributors; 2004 p. 84-5.

28. Patel DM, Patel MJ, Patel CN. Multi particulate system: A novel approach in gastro-retentive drug delivery. Int $\mathrm{J}$ Ayurveda Pharm Res 2011;2;96-106

29. Dey NS, Majumdar S, Rao ME. Multiparticulate drug delivery systems for controlled release. Trop J Pharm Res 2008;7:1067-75.

30. Garg R, Gupta GD. Progress in controlled gastroretentive delivery systems. Trop J Pharm Res 2008;7:1055-66.

31. Hoffman A. Pharmacodynamic aspects of sustained-release preparations. Adv Drug Deliv Rev 1998;33:185-99.

32. Hoffman A, Stepensky D. Pharmacodynamic aspects of modes of drug administration for the optimization of drug therapy. Crit Rev Ther Drug Carrier Syst 1999;16:571-639.

33. Sangekar S. Evaluation of the effect of food and the specific gravity of the tablets on gastric retention time. Int J Pharm 1987:35:34-53.
34. Mojaverian P, Vlasses PH, Kellner PE, Rocci ML. Effects of gender, posture, and age on the gastric residence time of indigestible solid: Pharmaceutical considerations. Pharm Res 1988;10:639-64.

35. Kavita K, Ashvini VR, Ganesh NS. Albumin microspheres. A unique system as drug delivery carriers for non-steroidal anti-inflammatory drugs. Int J Pharm Sci Rev Res 2010;5:10.

36. Swarbick J, Owen C, Amme H. Surfactants in pharmaceutical products and systems. In: Encyclopedia of Pharmaceutical Technology. Vol. 3. Taylor and Francis; 2003. p. 3590.

37. Dandagi MP, Masthiolimath SV, Gadad PA, Iliger RS. Mucoadhesive microspheres of propranolol hydrochloride for nasal delivery. Ind $\mathrm{J}$ Pharm Sci 2007;1:402-7.

38. Mathew ST, Devi GS, Prasanth VV, Vinod B. NSAIDs as microspheres. Int J Pharmacol 2008;6:225-34.

39. Phalguna Y, Venkateshwarlu BS, Gudas GK, Debnath S. HPMC Microspheres of zidovudine for sustained release. Int J Pharm Pharm Sci 2010;2:41-3.

40. Patel G, Tiwari A, Rabadia N. Floating microspheres as a novel tool for H receptor 2 blockers. Int Res J Pharm 2012;3:45-52.

41. Al Kassas RS, Gilligan CA, Liwan P. Processing factors affecting particle size and in vitro drug release of sustained-release ibuprofen microspheres. Int J Pharm 1993;94:59-67.

42. Lachmann L, Lieberman HA. Theory and Practice of Industrial Pharmacy. Bombay: Varghese Publishers; 2009.

43. Jain NK. Controlled, and Novel Drug Delivery. New Delhi: CBS Publishers and Distributors; 2004.

44. Rajput GC, Majmudar DF, Patel KJ, Patel NK, Thakor SR, Patel RR, et al. Floating drug delivery system a review. Pharm Ext 2010;1:43-5.

45. Jayaprakash S, Halith SM, Firthouse MP, Kulaturanpillai K, Abhijith, NM. Preparation and evaluation of biodegradable microspheres of methotrexate. Asi J Pharm Sci 2009;3:26-9.

46. Tirupati M, Rasala TM. Comparative Study of ionotropic gelation technique to entrap diltiazem HCL in the mucoadhesive microparticulate system. J Pharm Res 2010;3:1531-4.

47. Pradesh TS, Sunny MC, Varma HK, Ramesh P. Preparation of microstructured hydroxyapatite microspheres using oil in water emulsion. Bull Mater Sci 2005;28:383-90.

48. Harshad P, Bakliwal S, Gujarathi N, Rane B. Different methods of formulation and evaluation of mucoadhesive microsphere. Int J Appl Bio Pharm Tech 2010;1:1157-67.

49. Koziolek M, Garbacz G, Neumann M, Weitschies W. Simulating the postprandial stomach: Biorelevant test methods for the estimation of intragastric drug dissolution. Mol Pharm 2013;10:2211-21.

50. Kostewicz ES, Abrahamsson B, Brewster M, Brouwers J, Butler J, Carlert $\mathrm{S}$, et al. In vitro models for the prediction of in vivo performance of oral dosage forms. Eur J Pharm Sci 2014;57:342-66.

51. Parikh DC, Amin AF. In vitro and in vivo techniques to assess the performance of gastro retentive drug delivery systems: A review. Expert Opin Drug Deliv 2008;5:951-65

52. Saab M, Issa M, Samy W, El-Maradny H. Alternative approaches in formulating floating hollow tablets via sublimation technique: A platform tailored drug release profile. Pharmazie 2016;71:701-8.

53. Abouelatta SM, Aboelwafa AA, El-Gazayerly ON. Gastroretentive raft liquid delivery system as a new approach to release extension for carrier-mediated drug. Drug Deliv 2018;25:1161-74.

54. Pillay V, Fassihi R. Evaluation and comparison of dissolution data derived from different modified release dosage forms: An alternative method. J Control Release 1998;55:45-55.

55. Dürig T, Fassihi R. Evaluation of floating and sticking extended-release delivery systems: An unconventional dissolution test. J Control Release 2000;67:37-44.

56. Kong YL, Zou X, McCandler CA, Kirtane AR, Ning S, Zhou J, et al. 3D-printed gastric resident electronics. Adv Mater Technol 2019;4:1-11.

57. Eberle VA, Schoelkopf J, Gane PA, Alles R, Huwyler J, Puchkov M. Floating gastroretentive drug delivery systems: Comparison of experimental and simulated dissolution profiles and floatation behavior. Eur J Pharm Sci 2014;58:34-43.

58. Bai GE, Armenante PM, Plank RV, Gentzler M, Ford K, Harmon P. Hydrodynamic investigation of USP dissolution test apparatus II. J Pharm Sci 2007;396:2327-49.

59. Baxter JL, Kukura J, Muzzio FJ. Hydrodynamics-induced variability in the USP apparatus II dissolution test. Int J Pharm 2005;292:17-28.

60. Parikh RK, Parikh DC, Delvadia RR, Patel SM. A novel multicompartment dissolution apparatus for evaluation of floating dosage form containing poorly soluble weakly basic drug. Dissolution Technol 2006;13:14-9. 
61. Llabot JM, Manzo RH, Allemandi DA. Drug release from carbomer: Carbomer sodium salt matrices with potential use as a mucoadhesive drug delivery system. Int J Pharm 2004;276:59-66.

62. Nakagawa T, Kondo SI, Sasai Y, Kuzuya M. Preparation of floating drug delivery system by plasma technique. Chem Pharm Bull 2006;54;514-8.

63. Kumar A, Singh S, Sharma G, Sharma S, Verma A, Kaur R, et al. Formulation, optimization and evaluation of gastro-retentive floating microspheres ofnorfloxacin. Asian J Pharm Biomed Sci 2013;3:12-7.

64. Srivastava AK, Ridhurkar DN, Wadhwa S. Floating microspheres of cimetidine: Formulation, characterization, and in vitro evaluation. Acta Pharm 2005;55:277-85.

65. Sato Y, Kawashima Y, Takeuchi H, Yamamoto H. In vivo evaluation of riboflavin-containing microballoons for floating controlled drug delivery system in healthy human volunteers. J Control Release 2003;93:39-47.

66. Patil MP, Patil HS, Bharat WT, Vinod MT, Patil VR. Formulation and in-vitro evaluation of floating microspheres of acyclovir. Arch Pharm Sci Res 2009;1:194-8

67. Jain SK, Awasthi AM, Jain NK, Agrawal GP. Calcium silicatebased microspheres of repaglinide forgastroretentive floating drug delivery: Preparation and in vitro characterization. J Control Release 2005; 107:300-9

68. Aoki S, Ando H, Tatsuishi K, Uesugi K, Ozawa H. Determination of the mechanical impact force in the in vitro dissolution test and evaluation of the correlation between in vivo and in vitro release. Int J Pharm 1993;95:67-75.

69. Aoki S, Uesugi K, Tatsuishi K, Ozawa H, Kayano M. Evaluation of the correlation between in vivo and in vitro release of phenylpropanolamine HCL from controlled-release tablets. Int J Pharm 1992;85:65-73.

70. Schneider F, Hoppe M, Koziolek M, Weitschies W. Influence of postprandial intragastric pressures on drug release from gastroretentive dosage forms. AAPS PharmSciTech 2018;19:2843-50.

71. Garbacz G, Klein S, Weitschies W. A biorelevant dissolution stress test device Background and experiences. Exp Opin Drug Deliv 2010;7:1251-61.

72. Mandal UK, Chatterjee B, Senjoti FG. Gastroretentive drug delivery systems and their in vivo success: A recent update. Asian J Pharm Sci 2016;11:575-84.

73. Turner PV, Brabb T, Pekow C, Vasbinder MA. Administration of substances to laboratory animals: Routes of administration and factors to consider. J Am Assoc Lab Anim Sci 2011;50:600-13.

74. Razavi M, Karimian H, Yeong CH, Sarji SA, Chung LY, Nyamathulla S, et al. Gamma scintigraphic study of the hydrodynamically balanced matrix tablets of metformin HCL in rabbits. Drug Des Devel Ther 2015;9:3125-39.

75. Badve S, Sher P, Korde A, Pawar AP. Development of hollow/porous calcium pectinate beads for floating-pulsatile drug delivery. Eur J Pharm Biopharm 2007;65:85-93

76. Jain SK, Agrawal GP, Jain NK. A novel calcium silicate-based microspheres of repaglinide: In vivo investigations. J Control Release 2006;113:111-6.

77. Zhao Q, Gao B, Ma L, Lian J, Deng L, Chen J. Innovative intragastric ascaridole floating tablets: Development, optimization, and in vitro-in vivo evaluation. Int J Pharm 2015;496:432-9.
78. Kumar N, Soni S, Singh T, Kumar A, Ahmad FJ, Bhatnagar A, et al. Development and optimization of the gastro-retentive controlledrelease tablet of calcium-disodium edentate and its in vivo gamma scintigraphic evaluation. AAPS PharmSciTech 2015;16:1270-80.

79. Dhiman S, Singh TG, Rehni AK, Sood S, Arora S. Gastroretentive: A controlled release drug delivery system. Asian J Pharm Clin Res 2011;4:5-13

80. Steingoetter A, Weishaupt D, Kunz P, Mäder K, Lengsfeld H, Thumshirn $\mathrm{M}$, et al. Magnetic resonance imaging for the in vivo evaluation of gastric-retentive tablets. Pharm Res 2003;20:2001-7.

81. Gangurde HH, Chordiya MA, Tamizharasi S, Senthilkumaran K, Sivakumar T. Formulation and evaluation of sustained-release bioadhesive tablets of ofloxacin using 32 factorial design. Int J Pharm Investig 2011;1:148-56.

82. Dwivedi S, Kumar V. Floating drug delivery systems a concept of gastro retention dosages form. Int J Res Pharm Biomed Sci 2011;2:1413-26.

83. Klausner EA, Lavy E, Friedman M, Hoffman A. Expandable gastroretentive dosage forms. J Control Release 2003;90:143-62.

84. Shishu GN, Aggarwal N. Stomach-specific drug delivery of 5-fluorouracil using floating alginate beads. AAPS PharmSciTech 2007;8:48.

85. Pande AV, Vaidya PD, Arora A, Dhoka MV. In vitro and in vivo evaluation of ethyl cellulose-based floating microspheres of cefpodoxime proxetil. Int J Pharm Biomed Res 2010;1:122-8.

86. Khan FN, Dehghan MH. Enhanced bioavailability of atorvastatin calcium from the stabilized gastric resident formulation. AAPS PharmSciTech 2011;12:1077-86.

87. Yin L, Qin C, Chen K, Zhu C, Cao H, Zhou J, et al. Gastro-floating tablets of cephalexin: Preparation and in vitro/in vivo evaluation. Int $\mathrm{J}$ Pharm 2013;452:241-8.

88. Zhu X, Qi X, Wu Z, Zhang Z, Xing J, Li X. Preparation of multiple-unit floating-bioadhesive cooperative minitablets for improving the oral bioavailability of famotidine in rats. Drug Deliv 2014;21:459-66.

89. Qi X, Chen H, Rui Y, Yang F, Ma N, Wu Z. Floating tablets for controlled release of ofloxacin via compression coating of hydroxypropyl cellulose combined with an effervescent agent. Int J Pharm 2015;489:210-7.

90. Chen RN, Ho HO, Yu CY, Sheu MT. Development of swelling/ floating gastroretentive drug delivery system based on a combination of hydroxyethylcellulose and sodium carboxymethyl cellulose for Losartan and its clinical relevance in healthy volunteers with CYP2C9 polymorphism. Eur J Pharm Sci 2010;39:82-9.

91. Bomma R, Veerabrahma K. Development of gastroretentive drug delivery system for cefuroxime axetil: In vitro and in vivo evaluation in human volunteers. Pharm Dev Technol 2013;18:1230-7.

92. Meijerink CH, Changoer L, Blom W, Karimian H. Gastro-retentive Drug Delivery System. WO Patents 2014014348 A1; 2014.

93. Ranade AN, Ranpise NS, Ramesh C. Exploring the potential of gastro retentive dosage form in the delivery of ellagic acid and aloe vera gel powder for the treatment of gastric ulcers. Curr Drug Deliv 2014;11:287-97.

94. Abouelatta SM, Aboelwafa AA, Khalil RM, El-Gazayerly ON. Utilization of ionotropic gelation technique for bioavailability enhancement of cinnarizine: In-vitro optimization and in-vivo performance in humans. Drug Deliv 2015;7544:1-11. 